\title{
Review
}

\section{Xiaojun Du* \\ Sympatho-adrenergic mechanisms in heart failure: new insights into pathophysiology}

https://doi.org/10.1515/mr-2021-0007

Received March 24, 2021; accepted June 2, 2021;

published online October 21, 2021

\begin{abstract}
The sympathetic nervous system is activated in the setting of heart failure (HF) to compensate for hemodynamic instability. However, acute sympathetic surge or sustained high neuronal firing rates activates $\beta$-adrenergic receptor ( $\beta A R$ ) signaling contributing to myocardial remodeling, dysfunction and electrical instability. Thus, sympatho$\beta A R$ activation is regarded as a hallmark of $\mathrm{HF}$ and forms pathophysiological basis for $\beta$-blocking therapy. Building upon earlier research findings, studies conducted in the recent decades have significantly advanced our understanding on the sympatho-adrenergic mechanism in $\mathrm{HF}$, which forms the focus of this article. This review notes recent research progress regarding the roles of cardiac $\beta_{2} \mathrm{AR}$ or $\alpha_{1} \mathrm{AR}$ in the failing heart, significance of $\beta_{1} A R$-autoantibodies, and $\beta A R$ signaling through G-protein independent signaling pathways. Sympatho- $\beta A R$ regulation of immune cells or fibroblasts is specifically discussed. On the neuronal aspects, knowledge is assembled on the remodeling of sympathetic nerves of the failing heart, regulation by presynaptic $\alpha_{2} \mathrm{AR}$ of $\mathrm{NE}$ release, and findings on device-based neuromodulation of the sympathetic nervous system. The review ends with highlighting areas where significant knowledge gaps exist but hold promise for new breakthroughs.
\end{abstract}

Keywords: catecholamines; heart failure; sympathetic nervous system; $\beta$-adrenergic receptor; $\beta$-blocking therapy.

\section{Introduction}

The sympathetic nervous system (SNS) plays a central role in the regulation of cardiovascular function. The heart is

\footnotetext{
*Corresponding author: Xiaojun Du, Faculty of Physiology and Pathophysiology, School of Basic Medical Sciences, Xi'an Jiaotong University Health Science Center, 76 West Yanta Road, Xi'an 710061, Shanxi, China; Baker Heart and Diabetes Institute, 75 Commercial Road, Melbourne 3004, VIC, Australia, E-mail: xiaojun.du@baker.edu.au. https://orcid.org/0000-0001-5213-3911
}

densely innervated by sympathetic nerves that derived from cervical, cervical-thoracic and thoracic ganglias with each ganglion containing 200 to 1,000 neurons [1]. The sympathetic fibres enter the pericardial space, travel on the surface of atria and ventricles, and form a complex network including epicardial ganglionated plexi that modulate interactions between extrinsic and intrinsic cardiac autonomic nervous system [1]. Postganglionic sympathetic axons form nerve fibers that are densely localized in the sub-epicardium, the sinus atrial node and central conducting system.

$\beta$-Adrenergic receptors ( $\beta A R$ ) belong to a large family G-protein-coupled receptors (GPCR). In response to SNS activation, norepinephrine (NE) stored in neuronal vesicles is released into synaptic clefts by exocytosis in the mechanism, i.e. fusion of vesicular membrane with the pre synaptic neuronal membrane. Another mode of $\beta A R$ stimulation is through binding by circulating NE and epinephrine. Cardiomyocytes express different subtypes of $\beta A R$ with $\beta_{1} A R$ and $\beta_{2} A R$ being the most abundant subtypes representing approximately $80 \%$ and $15 \%$, respectively, of total $\beta A R$. Studies using the $\beta_{1} A R / \beta_{2} A R$ dual-knockout (KO) mouse model suggest presence of $\beta_{3} \mathrm{AR}$ that mediates mild negative inotropic effect. The classical signaling pathway of $\beta A R$ involves coupling with stimulatory G-protein (Gs), activation of adenylyl cyclase (AC) yielding cyclic adenosine monophosphate (cAMP), which activates protein kinase A (PKA). PKA subsequently phosphorylates a number of target proteins, like L-type $\mathrm{Ca}^{2+}$ channels, sarcoplasmic reticulum (SR) $\mathrm{Ca}^{2+}$ release channels (ryanodine receptors, RyR), SR $\mathrm{Ca}^{2+}$-ATPase (SERCA), troponin-I and phospholamban, leading to inotropic and chronotropic effects. $\beta_{2} \mathrm{AR}$ also couple to inhibitory Gi-protein (Gi), by which it counteracts Gs signaling including negative inotropy. Interestingly, in non-cardiomyocyte cells of the heart, like fibroblasts or immune cells, $\beta_{2} \mathrm{AR}$ is the predominant or the only subtype of $\beta A R$.

A hallmark of heart failure (HF) is enhanced sympatho$\beta$-adrenergic activity [2-4]. SNS hyperactivity might initially bear compensatory significance through enhancing cardiovascular functionality like inotropy and chronotropy, and maintenance of blood pressure for vital organ perfusion 


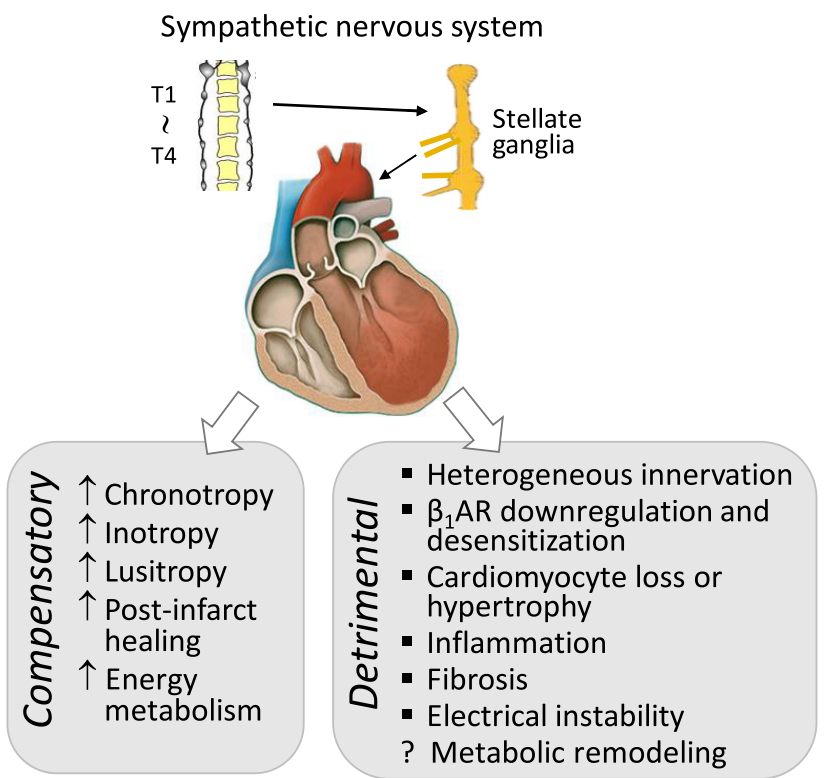

Figure 1: Cardiac sympatho- $\beta$-adrenergic signaling leads to compensatory as well as adverse consequences. Surges or sustained hyperactivity of sympathetic nervous drive to the heart might be compensatory for hemodynamic stability. Yet sympatho$\beta$-adrenergic overactivation acts as a double-edged sword to increase occurrence of detrimental events, most notably myocardial remodeling and $\beta_{1} A R$ downregulation/desensitization, which may further amplify central and efferent sympathetic activity. AR: adrenergic receptor.

(Figure 1). With sustained SNS- $\beta A R$ activation, however, the compensatory significance is diminishing whilst adverse cardiovascular remodelling at molecular and cellular levels becomes predominant leading to detrimental consequences (Figure 1).

Among GPCRs, $\beta A R s$ are most widely studied for structure, function, intracellular signalling and ligands. The aim of the present review is to provide insight overview of SNS- $\beta A R$ mechanisms in HF, particularly seminal studies leading to the current consensus, to assemble research progress achieved in the recent decades in this field, and to consider the unmet needs and key research challenges.

\section{Historic overview}

\section{Evidence for activation of the sympatho- $\beta A R$ system in $\mathbf{H F}$}

Clinical studies on patients with HF have contributed to the consensus that the enhanced sympatho- $\beta A R$ activity represents compensatory mechanism in response hemodynamic instability. By using a range of techniques [5], SNS overactivity in human HF patients can be ensured by: (1) increased circulating levels of NE; (2) enhanced spillover of cardiac sympathetic neurotransmitter, (3) augmented sympathetic neuronal firing rates [6], and (4) blunted $\beta_{1} A R$ response due to sustained stimulation by neuronal or circulation derived catecholamines. In patients with $\mathrm{HF}$, elevated circulating levels of $\mathrm{NE}$ and epinephrine bear prognostic implication [7]. Esler et al. [8] furthered this finding by measuring NE spillover through administration of a radiotracer $\left({ }^{3} \mathrm{H}-\mathrm{NE}\right)$ together with blood sampling using catheter positioned in the coronary sinus. Kinetics of regional sympathetic neurotransmission is able to determine, by using high-performance liquid chromatography, $\mathrm{NE}$ and a variety of its precursors or metabolites. Application of this technique to HF patients revealed enhanced NE release from cardiac sympathetic nerves together with faulty neuronal NE reuptake that further exaggerated rise in NE levels [4]. Patients with higher cardiac NE spillover rate had adverse long-term prognosis $[4,9,10]$. Direct recording of sympathetic nerve firing rates by using microneurography is able to determine muscle sympathetic nerve activity (MSNA). A recent meta-analysis of clinical studies on HF patients indicated that progressive increase in MSNA was observed in association with NYHF class [6], or with classification based on left ventricular ejection fraction [LVEF, i.e. heart failure with preserved ejection fraction (HFpEF), heart failure with midrange ejection fraction (HFmrEF), and heart failure with reduced ejection fraction (HFrEF)] [11]. Moreover, MSNA was correlated with heart rate, LV end-diastolic dimension (EDD), LVEF, brain natriuretic peptide (BNP) or plasma NE levels [11]. Likely due to non-invasive in nature, heart rate variability (HRV) has been commonly used to estimate autonomic nervous activity. Whilst increased lowerfrequency component of HRV is widely viewed as a parameter for enhanced SNS activity, studies using other more direct methodologies, as discussed above, suggest that the lower frequency of HRV is not directly related to cardiac sympathetic nervous activity [12]. Recently, nuclear imaging technique has been applied into the assessment of cardiac sympathetic nervous activity in patients with $\mathrm{HF}$ [13]. Current studies indicate that SNS imaging might be used for risk assessment [14], treatment monitoring, and matching treatment strategies with disease states. However, prospective and controlled trials are essential to confirm the usefulness of SNS imaging indices in guiding clinical management of HF with better outcomes. 
In the setting of $\mathrm{HF}$, activation of the sympatho- $\beta A R$ system has been well documented to exert pro-arrhythmic action, especially in the presence of substantial myocardial remodeling and fibrosis $[15,16]$. Enhanced sympatho- $\beta A R$ activity is known to evoke electrical instability via mechanisms involving induction of diastolic $\mathrm{Ca}^{2+}$ leaky through RyR $[17,18]$, and reduction in slow-component of delayed rectifier $\mathrm{K}^{+}$current $\left(I_{\mathrm{Ks}}\right)$ leading to prolongation of action potential duration [19]. Using cardiac NE spillover methodology to assess NE spillover and store, Brunner-La Rocca et al. [9] revealed in HF patients, that a lower NE store together with higher NE release predicted risk of fatality due to HF worsening, whilst the combination of large NE store and high NE spillover indicated risk of sudden death. Direct evidence for the pro-arrhythmic property of SNS activity derived from preclinical and clinical studies showing that sympathetic denervation is protective against ventricular tachyarrhythmias in diseased settings like acute MI, long QT syndrome, channelopathies, cardiomyopathy or HF [20-23]. A key role of the autonomic nervous system in the pathogenesis of atrial fibrillation has also been documented [24]. In pacing-induced canine model of HF, recording of nerve activity of the sympathetic stellate ganglion revealed augmented nerve firing that was directly associated with paroxysmal atrial tachycardia in these dogs with HF [25]. Using the same pacing-induced canine HF model, atrial tachyarrhythmias were markedly inhibited by ablation of bilateral stellate and thoracic ganglia [24]. For a commonly used anti-arrhythmic drug amiodarone, experimental and clinical studies have revealed its reserpine-like "sympatholytic" action, by which neurotransmitter storage of cardiac sympathetic nerves is partially exhausted [26-28]. Interestingly, chronic treatment with amiodarone to a rat model of dilated cardiomyopathy (DCM) induced by autoimmune myocarditis partially restored cardiac sympatho- $\beta_{1} \mathrm{AR}$ activity [28], suggesting the potential of chronic drug therapy-induced neuromodulation of the failing heart.

\section{Adverse biological consequences via $\beta A R$ signaling}

Numerous studies have established the notion that intense or sustained activity of the sympatho- $\beta$ AR system results in myocardial remodelling at molecular, cellular and organ levels and therefore is maladaptive (Figure 1). Observational studies have documented that in patients with $\mathrm{HF}$, elevated levels of physiological and biochemical parameters of SNS activity predict poor prognosis [4, 7, 29]. In preclinical studies, administration of $\beta$-agonists either as a toxic dosage or by continuous delivery, regimes simulating sympathetic storm or constant hyperactivity, results in cardiac damage and remodeling featured by cardiomyocyte loss, inflammatory infiltration, interstitial fibrosis and dysfunction [30, 31]. Supporting evidence also comes from studies using genetically modified mouse models with enhanced $\beta$-adrenergic signaling due to cardiac overexpression of $\beta A R$ or downstream signaling molecules like AC and PKA [32-34]. Understanding the downstream $\beta A R$ biology and cardiotoxic signalling has set up the foundation for the clinical use of $\beta$-blockers. Clinical use of $\beta$-blockers are beneficial in alleviating symptoms, limiting remodelling and improving cardiac function. Importantly, $\beta$-blocking therapy significantly improved long-term prognosis in patients from diagnosis of HF [35, 36]. Prolonged receptor exposure to catecholamines results in increased $\beta A R$-phosphorylation by PKA or GPCR kinases (GRKs). In addition to uncoupling $\beta A R$ from G-proteins, there is increased association of $\beta A R$ $\beta$-arrestins, which recruits other signal proteins thereby promoting non-classical signaling (vide infra). There is evidence that diverse $\beta A R$ signaling is more likely to occur in the failing heart contributing to adverse biological consequences. For instance, the cardiomyopathy phenotype seen in transgenic (TG) mice overexpression $\beta_{2} \mathrm{AR}\left(\beta_{2^{-}}\right.$ TG) was largely reversed by crossing with mice expressing dominant-negative mutant p38-mitogen-activated protein kinase (MAPK) [37]. In contrast, studies have also implicated detrimental or cardioprotective signaling via $\beta A R-\beta$ arrestin coupling [38, 39].

\section{$\beta_{1} A R$ downregulation and desensitization}

Under conditions of cardiac sympathetic hyperactivity together with elevated circulating levels of catecholamines, previous studies have shown $\beta_{1} A R$ downregulation, i.e. loss of surface membrane $\beta_{1} A R$ together with attenuated $\beta_{1} A R$ responsiveness, i.e. receptor desensitization $[40,41]$. The causal relationship of sympathetic overdrive and $\beta_{1} A R$ downregulation/desensitization in the failing heart has been well documented [41]. Clinically, augmented NE kinetics is correlated with the substantial loss of myocardial $\beta_{1} \mathrm{AR}$ in biopsies of HF patients [4, 8, 42]. Experimentally, in rapid-pacing induced canine HF model, isotope-trace based assay revealed a reverse correlation between interstitial NE levels and $\beta_{1}$ AR density $(r=-0.848, P<0.001)$ [43]. The process of $\beta_{1} A R$ downregulation is a consequence of sustained receptor stimulation that initiates receptor phosphorylation by GRKs and receptor binding by $\beta$-arrestins. $\beta$-arrestin-bound $\beta_{1} \mathrm{AR}$ then translocate from cell membrane 
to intracellular vesicles, where $\beta_{1} \mathrm{AR}$ either recycle back to membrane or undergo degradation [29, 44]. Another key factor contributing to the loss of $\beta_{1} A R$ in the failing myocardium is downregulation of gene transcription of $\beta_{1} \mathrm{AR}$ (but not $\beta_{2} \mathrm{AR}$ ), which is commonly observed by a scale of $50 \%-70 \%$ relative to controls by studies on numerous animal models of HF or myocardial biopsy of from human patients. Using quantitative autoradiography, Elnatan et al. [45] studied biopsies from various regions of the heart from $\mathrm{HF}$ patients, and observed that $\beta_{2} \mathrm{AR}$ accounted for $36 \%-72 \%$ of total $\beta \mathrm{AR}$, indicating substantial loss of $\beta_{1} A R$. Desensitization of remaining $\beta_{1} A R$ starts from receptor phosphorylation either by PKA or by GRKs, followed by $\beta$-arrestin binding but uncoupling from G-proteins $[40,46]$. Importantly, distinct differences exist between $\beta_{1} \mathrm{AR}$ and $\beta_{2} \mathrm{AR}$ with $\beta_{2}$-subtype maintaining its density albeit receptor relocation occurs, which is accompanied with altered intracellular signaling (vide infra). However, earlier studies also showed an enhanced $\beta_{2} A R-G i$ signaling in the failing heart, likely due to increased Gi-protein abundance and $\beta_{2} \mathrm{AR}$ phosphorylation by PKA that increases $\beta_{2} \mathrm{AR}-\mathrm{Gi}$ coupling whereas reduces Gscoupling [47]. The $\beta_{2} \mathrm{AR}-\mathrm{Gi}$ coupling is known to exert inhibitory regulation of $\beta_{1} \mathrm{AR}$ responsiveness $[40,46]$.

\section{Establishment of the $\beta$-blocking therapy for HF patients}

It has been nearly 60 years since the initial discovery made by James Black et al. [48] on the first $\beta$-antagonist propranolol. This work was followed by subsequent earlier clinical testing on patients with HF [49]. Swedish cardiologist Dr. Waagstein pioneered clinical testing during 1970s for treatment of patients with chronic HF using $\beta$-blockers [50]. Although the very first paper was published in 1975 [49], it took almost two decades for this class of drugs to be accepted as a front-line medicine for patients with $\mathrm{HF}[51,52]$. The current consensus is that $\beta$-blockers may protect the heart against adverse biological effects owing to sympathetic overdrives. Additionally, $\beta$-blockers might also suppress activity of the renin-angiotensin-aldosterone system by blocking renin release following renal sympatho- $\beta$ AR activation, and inhibit inflammatory signalling [5, 44]. Earlier and recent meta-analysis of randomized clinical trials have confirmed the efficacy of $\beta$-blocking therapy on patients with the spectrum of HF syndrome, judged by hard clinical outcomes like re-hospitalization, sudden cardiac death, cardiovascular mortality or all-cause mortality $[35,36]$. There is also evidence for $\beta$-blocking therapy to re-sensitize the suppressed $\beta_{1}$ AR signaling in the failing heart [44].

\section{Recent research progress}

Pioneering research conducted during 1980s-1990s established the foundation of the sympatho- $\beta$ AR mechanism in HF with successful clinical translation. Upon this foundation, significant progress has been achieved in recent decades on the role of SNS-AR system in HF pathophysiology, which will be assembled in this main section. Selected research aspects cover from the role in cardiac $\beta_{2} \mathrm{AR}$ or $\alpha_{1} A R, \beta A R$ signaling through G-protein independent pathways, significance of $\beta_{1} A R$-autoantibodies, to sympatho- $\beta A R$ regulation of immune cells or fibroblasts. On the sympathetic nerves per se, discussion will be directed on the remodeling of sympathetic nerves in the failing heart, presynaptic regulation of NE release by $\alpha_{2} \mathrm{AR}$, and findings on device-based central neuromodulation.

\section{Increased appreciation on the role of $\beta_{2} A R$ signaling in heart failure}

Recent studies on $\beta_{2} A R$ have demonstrated (1) significant receptor redistribution on cell membrane, (2) adverse signaling, and (3) increased potential of pro-arrhythmic action. In the setting of ischemia or simulated ischemic conditions, activation of $\beta_{2} \mathrm{AR}$ is cardioprotective in large part through its Gi-signalling that opposes $\beta A R$-Gs signalling [53]. Alternations in $\beta_{2} \mathrm{AR}$ signaling in the failing myocardium are also revealed. In the failing heart, GRK2 is activated and mediates $\beta_{2} \mathrm{AR}$ phosphorylation by which $\beta_{2} A R-G i$ signaling is enhanced, which might facilitate development of HF under certain diseased conditions, such as chronic pressure-overload [54]. Importantly, $\beta_{2} \mathrm{AR}$ signaling pattern is altered in the failing myocardium. Upon ligand binding, activation of $\beta_{1} A R$ of cardiomyocytes increases intracellular level of cAMP and PKA activity in a scale of virtually whole cell, while $\beta_{2}$ AR-mediated intracellular changes are restricted to a limited compartment $[55,56]$. Such differences are due to diverse receptor localization with $\beta_{1} \mathrm{AR}$ more evenly distributed on cellular membrane while $\beta_{2}$ ARs are embedded within transverse tubules (t-tubules) where other signal proteins, like caveolin-3 and G-proteins, are richly represented forming multi-protein clusters (signalsomes) (Figure 2) [57]. In the failing heart, cardiomyocytes are characterized by overt disruption of t-tubules where synchronization of events like $\mathrm{Ca}^{2+}$-influx triggered $\mathrm{SR} \mathrm{Ca}^{2+}$ release (CICR) occurs [58]. T-tubules also co-localize $\beta_{2} A R$-signalsomes critical for compartmentalized $\beta_{2} \mathrm{AR}$ signaling (Figure 2) [57]. With loss of t-tubules [56, 57] as well as caveolin-3 [59], $\beta_{2} \mathrm{AR}$ 

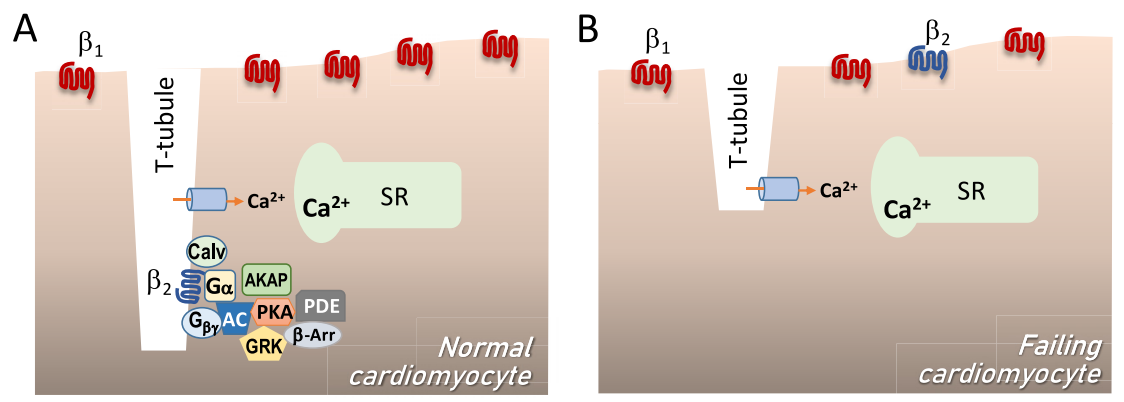

Figure 2: T-tubule localized $\beta_{2} A R$ signalosomes and redistribution of $\beta_{2} A R$ in the failing cardiomyocyte. A. Cardiomyocytes are rich in t-tubular structures, where sarcolemma membrane invaginate into the internal space of the cell body. T-tubules contain abundant lipid microdomains and caveolae and are rich in ion channels, e.g. L-type calcium channels, important for membrane potential and excitation-contraction (EC) coupling and mobilization of sarcoplasmic reticulum (SR) $\mathrm{Ca}^{2+}$ pool. T-tubules are the location of cluster of signaling proteins including G-proteins, adenylyl cyclase (AC), G-protein receptor kinase (GRK), A-kinase anchoring proteins (AKAP), protein kinase A (PKA), protein phosphatase $2 A$, and phosphodiesterases (PDE), forming highly efficient signalosomes. $\beta_{2} A R$ are also highly enriched in the caveolae/lipid microdomain of t-tubules where it induces local cAMP-PKA and $\mathrm{Ca}^{2+}$ signals. In comparison, $\beta_{1} \mathrm{AR}$ are largely distributed throughout sarcolemma membrane and mediate a global cAMP-PKA and intracellular $\mathrm{Ca}^{2+}$ signals. $\mathrm{B}$. In the failing myocardium, there is significant loss of $t$-tubular network and hence partial disintegration of signaling clusters. Hence, $\beta_{2} A R s$ undergo redistribution from t-tubules to sarcolemma membrane, which renders $\beta_{2} A R$ signaling upon ligand binding similar to that of $\beta_{1} A R$. AR: adrenergic receptor.

redistribute to cell surface and, upon ligand stimulation, alters the mode of signaling akin to that of $\beta_{1} A R$ (Figure 2) [57, 59]. Surface scans of cardiomyocytes using scanning ion conductance microscopy (SICM) showed that structural alteration of t-tubules of failing cardiomyocytes were associated with regional change of functional $\beta A R s$, in particular, compartmented $\beta_{2}$ AR-cAMP signal was disturbed. Instead, $\beta_{2} A R-c A M P$ signal was observed to propagate along the cardiomyocyte [56, 57]. Indeed, an earlier study by Kaumann et al. [60] showed that in failing myocardium of patients with DCM or ischemic cardiomyopathy, stimulation of $\beta_{2} \mathrm{AR}$ and $\beta_{1} \mathrm{AR}$ yielded similar extent of downstream signaling and functional responses.

Ventricular dilatation and myocardial remodelling (including hypertrophy and fibrosis) form the proarrhythmic substrates [16]. In this setting, sympatho$\beta A R$ activation acts as a powerful trigger of arrhythmias. An earlier study by us provided the direct evidence for SNS activation as a trigger of ventricular arrhythmias [15]. Using in situ perfused heart from rats with chronic myocardial infarction (MI) and HF, electrical stimulation of cardiac sympathetic nerves was potent in inducing ventricular tachyarrhythmias with the severity of arrhythmias dependent on the intensity of nerve stimulation and the infarct size [15]. We observed that SNS stimulation-evoked arrhythmias could only be inhibited by the combined use of $\beta_{1}$ - and $\beta_{2}$-selective antagonists. Other studies also highlighted the role of $\beta_{2} \mathrm{AR}$ in the onset of ventricular tachyarrhythmias in the failing heart $[18,61]$. In a rabbit model of HF with severe cardiac remodeling and fibrosis, induced by combination of aortic valve regurgitation and pressure-overload, administration of the $\beta_{2}$-agonist zinterol evoked ventricular tachyarrhythmias in failing hearts while having no effect in normal hearts [18]. This pro-arrhythmic action of zinterol was abrogated by the concomitant use of the $\beta_{2^{-}}$ antagonist ICI-118,551 while blockade of $\beta_{1} \mathrm{AR}$ was ineffective. In ventricular myocytes isolated from failing rabbit hearts, stimulation of $\beta_{2} \mathrm{AR}$ induced increased extent of $\mathrm{Ca}^{2+}$ transient amplitudes, SR Ca ${ }^{2+}$ leaking and phosphorylation of phospholamban [18]. In this $\mathrm{HF}$ rabbit model, expression and function of $\beta_{1}$ AR were markedly downregulated or attenuated whilst that of $\beta_{2} \mathrm{AR}$ was maintained, changes emulating that seen in human failing heart $[18,44]$. Hence $\beta_{2}$-AR activation is arrhythmogenic in the failing heart by increasing the SR-Ca ${ }^{2+}$ loading and the spontaneous release of $\mathrm{Ca}^{2+}$ from the SR. In another study on LV myocardium from advanced HF patients, distinct pro-arrhythmic role of $\beta_{1} \mathrm{AR}$ and $\beta_{2} \mathrm{AR}$ signaling was observed [61]. Specifically, treatment of the failing human myocardium with selective $\beta_{2^{-}}$, but not $\beta_{1}$-agonists enhanced conduction velocity, shortened action potential duration, and increased intracellular $\mathrm{Ca}^{2+}$ transients. $\beta_{1} \mathrm{AR}$ stimulation only induced automaticity in Purkinje fibers of the sub-endocardium, whereas $\beta_{2} \mathrm{AR}$ stimulation significantly induced not only automaticity of Purkinje fibers of the sub-endocardium, but also $\mathrm{Ca}^{2+}$-mediated delayed afterdepolarizations in the sub-epicardium and 
mid-myocardium. This heterogeneous ectopic activity by $\beta_{2} \mathrm{AR}$ stimulation suggests that in human failing myocardium, $\beta_{2} \mathrm{AR}$ signaling becomes more important than $\beta_{1} \mathrm{AR}$ in inducing electrophysiological abnormalities across the entire layer of the ventricular wall.

Using genetically modified mouse models with overexpressing in cardiomyocytes of genes encoding $\beta_{1} \mathrm{AR}$, $\beta_{2} \mathrm{AR}$ Gs $\alpha$, AC or PKA, studies have demonstrated similar cardiomyopathy phenotypes, notably age-dependent onset of HF, fibrosis, ventricular arrhythmias and premature death [32, 33, 62-64]. With aging, $\beta_{2} \mathrm{AR}$ transgenic $\left(\beta_{2}-\mathrm{TG}\right)$ mice exhibited fibrotic cardiomyopathy and premature deaths due either to HF or sudden death $[32,65,66]$. In a telemetry study on conscious $\beta_{2}$-TG mice [64], we found that administration of the $\beta_{2}$-antagonist ICI-118,551 significantly reduced the frequency of ventricular tachyarrhythmias, effect only seen in $\beta_{2}$-TG mice with advanced age and severe cardiac fibrosis [64]. This finding suggests that the presence of overt fibrosis as the substrate permits the pro-arrhythmic effect of $\beta_{2} \mathrm{AR}$ activation.

Using $\beta_{2}$-TG mice at young ages when overt cardiomyopathy is still absence, we studied influence by enhanced $\beta_{2} \mathrm{AR}$ activity on cardiac adaptation to disease challenge by transverse aorta constriction (TAC) or MI. $\beta_{2^{-}}$ TG mice tolerate poorly to chronic pressure-overload with facilitated onset of HF with exacerbated cardiac remodeling, and premature deaths $[67,68]$. Under conditions of chronic MI, however, $\beta_{2}$-TG mice displayed better preserved LV function and less severe HF relative to control littermates [69]. Thus, the effect of enhanced activity of $\beta_{2} \mathrm{AR}$ on HF is aetiology-dependent.

Clinical and experimental studies have generated strong evidence for a vital role of SNS- $\beta$ AR in the pathogenesis of Takatsubo cardiomyopathy (or stress cardiomyopathy). In patients with Takatsubo cardiomyopathy, circulating levels of catecholamines were markedly increased, even much higher compared with that of patients diagnosed with acute MI [70]. Experimentally, exposure to large doses of $\beta$-agonists (isoproterenol, ISO, or epinephrine up to $500 \mathrm{mg} / \mathrm{kg}$ ) is able to induce temporal and reversible LV dysfunction, and that $\beta_{2} \mathrm{AR} / \mathrm{Gi} \alpha$ signalling is critical in Takatsubo cardiomyopathy with acute HF. Paur et al. [71] reported in rats the presence of relatively higher $\beta_{2} \mathrm{AR}$ density at the apical myocardium relative to the basal region of the heart. Stimulation of myocardial $\beta_{2} \mathrm{AR}$ preferentially activates the Gi-mediated cardio-suppressant effect that was more prominent in the apical than the basal regions. Accordingly, use of $\beta_{2} \mathrm{AR}$ antagonist levosimendan was cardioprotective against acute of LV dysfunction and fatality [71].

\section{$\beta A R$ signaling through EPAC and GRK/ $\beta$-arrestins}

One of the breakthroughs in $\beta A R$ signalling is the demonstration of the downstream signaling via exchange protein directly activated by cAMP (EPAC), which was initially discovered in 1998 [72]. cAMP is the most welldocumented signaling molecule that is generated by membrane-bound AC upon $\beta A R$ stimulation and subsequently activates PKA. Identified as novel cAMP-binging proteins, EPAC is now emerging as an alternative cAMP effector. Binding of cAMP to the regulatory subunit of EPAC leads to conformational change with exposure of its catalytic region. EPAC1 and EPAC2 are structurally similar multi-domain proteins. Whilst EPAC2 expression is restricted to neuroendocrine tissues, EPAC1 is ubiquitously expressed with a high expression level in the heart. EPAC1 is known to form signalosomes with partner proteins including $\beta$-arretins, $\mathrm{Ca}^{2+} /$ calmodulin-dependent protein kinase (CaMK-II), a small G-protein Rap, within the subcellular compartments, rendering EPAC1 as a multifunctional signaling molecule. There is also evidence for mitochondria-localized EPAC1 that mediates cardiomyocyte death by promoting mitochondrial $\mathrm{Ca}^{2+}$ overload and opening of mitochondrial permeability transition pore (mPTP) [73]. Mitochondrial cAMP promotes mitochondrial $\mathrm{Ca}^{2+}$ influx from the ER via VDAC1/ Mcu (voltage-dependent anion-selective channel-1/mitochondria calcium uniporter) through recruitment of EPAC1 [74]. Indeed, mitochondria $\mathrm{Ca}^{2+}$ level plays a role in the regulation of ATP biosynthesis [75]. It remains to be investigated whether such mitochondria-EPAC1 participates in the regulation of energy metabolism in cardiac physiology and, more importantly in failing cardiomyocytes. It has been shown that cAMP can also be generated by soluble AC (sAC), which is activated by $\mathrm{Ca}^{2+}$ signal. This extends our understanding on compartmented sAC/cAMP/EPAC signalling. It is likely that SAC/ cAMP/EPAC signaling allows for subcellular fine turning of cAMP-mediated signalling that may be directly (via AC/ cAMP) or indirectly (via $\mathrm{Ca}^{2+}$ signal) linked to the classical $\beta A R / G s / A C / c A M P / P K A$ signaling.

Cardiac expression of EPAC1 was markedly increased in various animal models of pathological cardiac remodelling such as chronic catecholamine infusion, pressure overload induced by TAC [72], or in hearts of human patients with end-stage HF due to DCM or ischemic cardiomyopathy [72, 73, 76]. By employing specific gene deficient models or inhibitor, several studies have investigated the role of EPAC1 under diseased 
conditions. A recent study on both EPAC1-deficient mouse model and EPAC1 inhibitor (AM-001) provided evidence for cardioprotective effects by inactivating EPAC1 in various forms of cardiac stress [77]. Activation of EPAC1 has been shown to disturb $\mathrm{Ca}^{2+}$ homeostasis, enhance reactive oxygen species (ROS) generation, stimulate gene expression and exacerbate myocardial remodelling [78]. EPAC1 or EPAC2 KO mice did not exhibit change in baseline cardiac function. Under diseased conditions such as chronic $\beta$-agonist stimulation or TAC, however, EPAC1-KO mice exhibited reduced severity of cardiac hypertrophy, cardiomyocyte apoptosis or fibrosis relative to wild-type controls $[79,80]$. Pereira et al. [81] studied EPAC1 and EPAC2 deficient mice subjected to TAC for 3-weeks, and observed that stimulation of $\beta_{1} A R$, but not $\beta_{2} \mathrm{AR}$, mediated a CAMK-II-dependent SR-Ca ${ }^{2+}$ leak and arrhythmias, which were abolished in EPAC2-KO, but not in EPAC1-KO mice, despite the fact that EPAC2 protein was undetectable in the heart tissues. Whether such action occurs in the setting of HF remains to be investigated.

Significant breakthroughs have also been made in $\beta A R$ signaling through G-protein receptor kinases (GRKs)/ $\beta$-arrestins. Among GRK family members, GRK2, GRK3 and GRK5 are highly expressed in the heart [82]. GRKs, particularly GRK2 and GRK5, mediate phosphorylation of $\beta A R$ that promotes (a) receptor binding by GPCR adapter proteins $\beta$-arrestins with subsequent $\beta A R$ desensitization/downregulation, and (b) $\beta$-arrestinmediated signaling. In diseased and failing hearts, expression and activity of GRK2 and GRK5 are elevated. Therapeutic implication of GRK overactivity is at two folds: First, GRK-phosphorylates $\beta A R$ thereby leading to receptor downregulation and desensitization. Causal role of GRK in mediating $\beta$ AR downregulation/desensitization is indicated by studies using mouse models of GRK2 overexpression, or expression of C-terminal domain ( $\beta A R K c t)$ that prevents GRK2 translocation to the membrane thereby sparing $\beta A R$ from phosphorylation [83]. By crossing $\beta$ ARKct-TG mice with genetic mice with cardiomyopathy or subjected to chronic disease stress, studies showed improvement in cardiac function and chamber dilatation, and reduction in premature death [83]. Second, GRK/ $\beta$-arrestin signaling mediate a large part of intracellular events evoked by $\beta A R$ stimulation in a G-protein independent fashion. GRK2 is known to inhibit insulin signaling pathway and therefore may interfere with cardiac and systemic metabolism [84, 85]. In patients with acute MI, elevated expression of lymphocyte GRK2 during the acute phase was correlated with LV dysfunction and dilatation determined acutely or during a 2-year follow-up period, implying that GRK2 level predicts adverse cardiac outcomes in MI [86]. In a cryogenic MI mouse model, Ciccarelli et al. [87] reported that inhibition of GRK2 using a peptide (C7) improved mitochondrial morphology and function together with improvement in contractile function. Lymperopoulos et al. [88] reported that GRK2 signaling is responsible for downregulation of presynaptic $\alpha_{2} \mathrm{AR}$, that promotes $\mathrm{NE}$ release. In addition, GRK2 activates NF- $\kappa B$ signaling thereby promoting inflammation and hypertrophy. Thus, it is important to further establish the role of GRK2 in HF and test targeted therapeutic interventions. Unlike previous view of functionally interchangeable, recent studies have revealed significant differences between $\beta$-arresins1 and $\beta$-arrestin2 [83, 89, 90]. Notably, $\beta$-arrestin2, but not $\beta$-arrestin1, mediates positive inotropy via activation of SERCA2a [91], protects heart against apoptosis through transactivation of epidermal growth factor receptor (EGFR) and extracellular signal-regulated kinase (ERK)1/2 activation, and antagonizes NF- $\mathrm{BB}$ inflammatory signaling [91-94]. In contrast, there is ample evidence for detrimental cardiac effects mediated by $\beta$-arrestin1. Unlike $\beta$-arrestin2, $\beta$-arrestin1 is unable to transactivate EGFR which mediates cardioprotective signaling $[83,89]$. When studied under stressed conditions like MI, $\beta$-arrestin1 KO mice were not only spared of $\beta_{1} \mathrm{AR}$ downregulation/ desensitization, but also had reduced apoptotic cell death, ventricular remodelling and dysfunction and mortality [89]. Thus, specific pharmacological interventions that regulate the counteractive signaling mediated by $\beta$-arrestin 1 and $\beta$-arrestin 2 would be expected to be useful in HF therapy [83].

\section{Emerging evidence for $\beta_{1} A R$-Gi $\alpha$ coupling}

Whilst traditional view of $\beta A R-G i \alpha$ coupling is restricted to $\beta_{2}$-subtype, there have been studies showing $\beta_{1} A R-G i \alpha$ interaction. Belevych et al. reported that in cultured cardiomyocytes, $\beta_{1} \mathrm{AR}$ mediated signaling, measured as $\mathrm{Ca}^{2+}$ influx via L-type $\mathrm{Ca}^{2+}$ channel, was blunted by simultaneous activation of protein kinase $\mathrm{C}$ (PKC), effect that was abolished by pertussis toxin, suggesting coupling of $\beta_{1} A R$ and Gai/o [95]. Martin et al. [96] also observed in transfected CHO cells, switching from Gs to Gi coupling following PKA-mediated phosphorylation of $\beta_{1} \mathrm{AR}$. These in vitro findings have gained support by recent in vivo studies. In $\beta_{1}$-TG mouse model of cardiomyopathy, knockout of Gai2 worsened the severity of cardiomyopathy and increased premature death [97], implying that at 


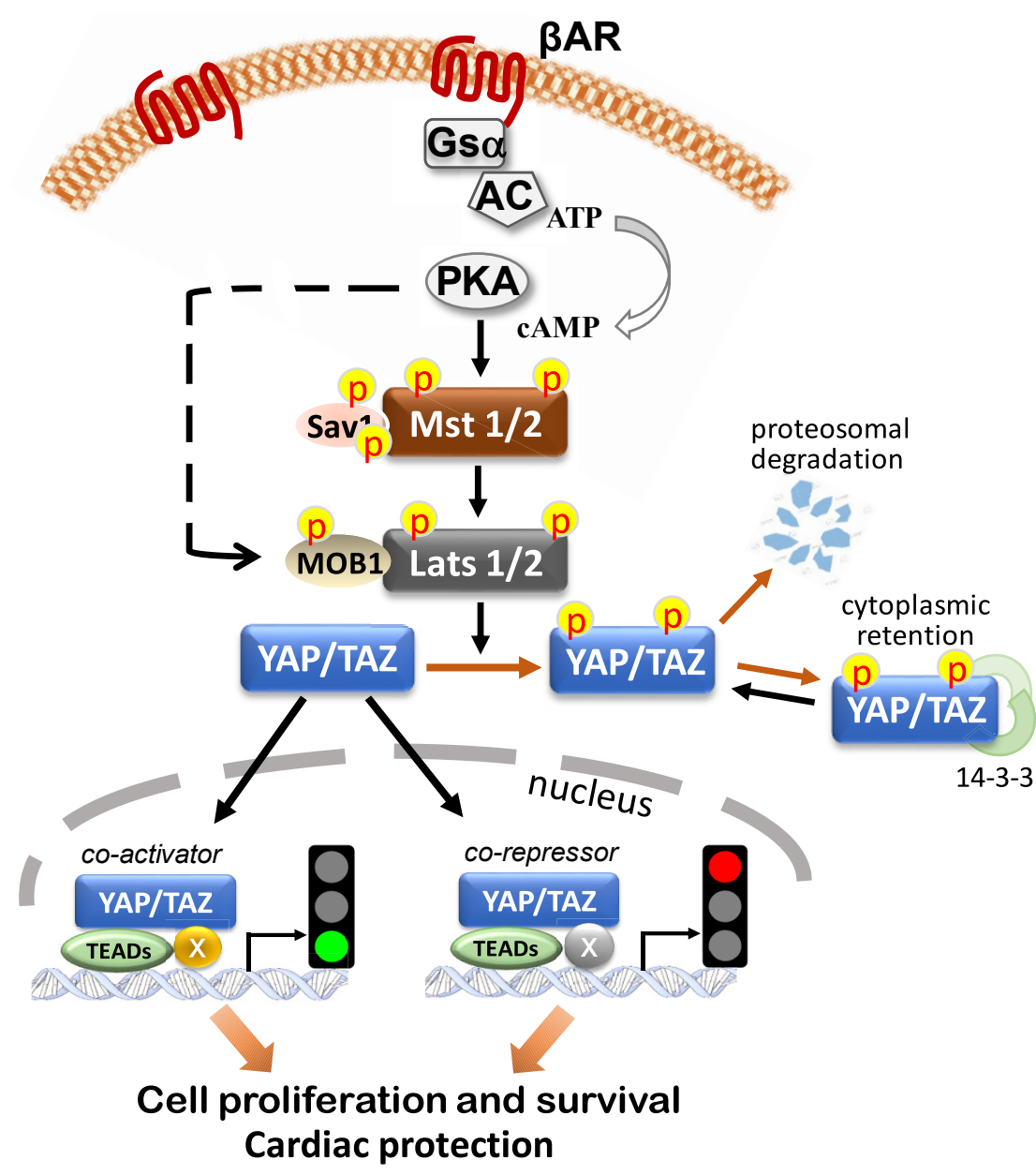

Figure 3: Diagram depicting $\beta A R$ signaling through the Hippo pathway in the heart. There is strong evidence for coupling of $\beta$-adrenergic and Hippo signaling pathways in the myocardium. $\beta A R$ stimulation by genetic or pharmacological means effectively activates Hippo signaling featured by activation of upstream kinases Mst1 (mammalian strile-20 like kinase1) and Lats (large tumour suppressor homolog), and enhanced inhibitory Ser ${ }^{127}$-phosphorylation of YAP (yes-associated protein) and its paralogue TAZ (transcription coactivator with PDZ-binding motif). The latter results in cytoplasmic retention of YAP with increased binding to scaffold protein 14-3-3 and subsequent degradation via the ubiqutine/proteasome system. As a consequence, the activity of YAP as transcription co-activator or co-repressor, is turned off leading to altered expression of numerous YAP-target genes. Studies in vitro also suggest $\beta A R / P K A-m e d i a t e d$ direct Lats activation bypassing Mst (broken line). MOB1: Mps one binder kinase activator like 1; Sa: salvador homologue; TEAD: TEA-domain transcription factor. $\otimes$ Indicates epigenetic factors. least under diseased conditions, there exists interaction between $\beta_{1} \mathrm{AR}$ and Gia. Carvedilol is a non-selective $\beta$-blocker with 13 -fold more potent as a competitively $\beta_{2^{-}}$ than $\beta_{1}$-antagonist in human heart tissues [98]. Interestingly, carvedilol binding to $\beta_{1} \mathrm{AR}$ initiates $\beta_{1} \mathrm{AR}$-Gi $\alpha$ interaction that favours $\beta$-arrestin-mediated signaling whereas $\beta_{1}$ AR-Gs signaling is inactivated [99]. In another study on cardiomyocytes prepared from diabetic mice, treatment with carvedilol promoted $\beta_{1} \mathrm{AR}$-Gi $\alpha$ coupling leading to activated signaling through phosphatidylinositol-3-kinase (PI3K)/Akt/nitric oxide synthase (NOS3)/protein kinase G (PKG) [100]. This signaling pathway is cardioprotective measured by reduced myocardial apoptosis or hypertrophy, improved myocardial energy status, and better preservation of contractile function [100]. Thus, it is likely that under diseased settings, $\beta_{1}$ AR-Gi $\alpha$ interaction activates downstream signaling pathways that involve $\beta$-arrestin, PI3K and cGMP/PKG. Such interaction is facilitated by binding to $\beta_{1} \mathrm{AR}$ of carvedilol as a biased-ligand (but not by other $\beta$-blockers).

\section{BAR activates Hippo signaling pathway}

Recent studies have documented $\beta$ AR-Hippo pathway signaling. The Hippo pathway is a highly conserved signalling that plays a vital role in the regulation of organ size during development [101]. The main signal output of Hippo pathway is through yes-associated protein (YAP), which is a transcription co-regulator (Figure 3). YAP orchestrates with transcription factors, like TEA domain transcription factors (TEADs) and regulates expression of numerous target genes. The nuclear localization of YAP is essential for its transcriptional activity. YAP activity is suppressed by upstream kinases, Mst1 (mammalian sterile-like kinase-1) and Lats (large tumour suppressor homolog), through $\mathrm{Ser}^{127}$-phosphorylation of YAP [101]. Recent studies have implicated a key role of Hippo-YAP pathway in heart disease [101-104]. Whereas enhanced YAP activity facilitates post-MI cardiac healing by promoting cardiomyocyte regeneration [101], activation of Hippo signalling with YAP-inactivation, like transgenic overexpression of Mst1 (Mst1-TG) or cardiomyocyte- 
restricted knockout of YAP (YAP-cKO) or TEAD1 (TEAD1cKO), similarly results in DCM phenotype with severe interstitial fibrosis [104-108], implying a common mechanism involved. Studies have shown activated cardiac Hippo signalling with YAP inactivation in patients or animals with a variety of cardiomyopathies [31, 63, 102, 109, 110].

Recent studies have demonstrated regulation of the Hippo pathway by GPCRs. $\beta$ AR-Hippo pathway coupling was firstly implicated by Yu et al. [111] who discovered in mammalian cell lines that overexpression of Gs-coupled glucagon receptor, $\beta_{2} \mathrm{AR}$ or a constitutively active form of Gs $\alpha$, increased Ser ${ }^{127}$-YAP phosphorylation. In cell lines like mouse embryonic fibroblasts, Kim et al. also showed that activation of PKA using the AC activator forskolin induced Ser ${ }^{127}$-YAP phosphorylation indicating YAP inactivation by cAMP/PKA signalling [112]. In human adenocarcinoma cell line, stimulation with catecholamines induced Ser ${ }^{127}$-YAP phosphorylation, which was prevented by propranolol [113]. Several lines of recent findings, largely from in vivo studies, have implicated that activation of $\beta$ AR-Hippo signaling with YAP inactivation contribute to pathogenesis of heart disease (Figure 3). First, pharmacological (i.e. ISO) or transgenic activation of $\beta A R$ (i.e. $\beta_{1}-\mathrm{TG}$, $\beta_{2}$-TG) leads to cardiac upregulation of Mst1 [31, 63]. ISO stimulation also induces a dose- and time-dependent Ser ${ }^{127}$-YAP phosphorylation in the heart [31]. Second, activation of Hippo signaling by $\beta A R$ stimulation involves PKA and Mst1. Cell experiments showed that ISO-mediated Mst1 upregulation/YAP phosphorylation were abolished by PKA inhibitors but mimicked with the use of forskolin, implying PKA-dependent signalling (Figure 3) [31]. In $\beta_{1}$-TG mice with cardiomyopathy, inactivation of Mst1 by crossing with TG mice harbouring dominant-negative mutant Mst1 gene (dnMst1-TG with inhibition of native Mst1 activity) largely abolished cardiomyopathy phenotypes (e.g. inhibited cardiomyocyte apoptosis and fibrosis, and improved LV function) [63], findings that underscore a pivotal role of Mst1 signaling in this $\beta_{1}$-TG model of cardiomyopathy. Similar protection against ISO-cardiotoxicity was observed in Mst1-KO mice [63]. Third, the operation of $\beta A R$-Hippo signalling pathway promotes cardiac expression of genes like galectin-3 (pro-inflammatory and pro-fibrotic protein), CTGF (connective tissue growth factor (CTGF) and Bcl-2 interacting mediator of cell death (BIM), an upstream pro-apoptotic protein) that are known to contribute to the development and worsening of heart disease (Figure 3) [31, 107, 114, 115]. In dnMst1-TG mice [108], ISO-induced upregulation of galectin-3 and BIM was significantly inhibited [31]. In contrast, in Mst1-TG model with activated Hippo signaling and a markedly high galectin-3 content, ISO-induced net increment in galectin-3 expression was 10-times greater relative to that in control animals [31]. Finally, in cardiomyoblast H9c2 cells, ISO-induced Ser ${ }^{127}$-YAP phosphorylation and galectin-3 upregulation, effects that were simulated by siRNA-mediated YAP knock-down [31]. Similarly, in the Mst1-TG model with YAP inactivation [31], RNA sequencing revealed that $68 \%$ of YAP-target genes are upregulated [31]. These findings indicate that in addition to transcription co-activator, YAP also acts as a co-repressor for expression of certain genes (such as galectin-3), hence removal of YAP inhibitory signal as a result of activation of the $\beta A R$-Hippo signaling results in upregulation of these genes (Figure 3) [31]. With increasing amount of evidence for a role of Hippo pathway in heart disease, further research is warranted to investigate the $\beta$ AR-Hippo signaling in development of HF and the therapeutic effect using $\beta$-blockers.

\section{Autoantibodies against $\beta A R$}

Autoantibodies against $\beta_{1} \mathrm{AR} \quad\left(\beta_{1} \mathrm{AR}-\mathrm{AAb}\right)$ could be detectable in $30 \%-90 \%$ of patients with DCM or up to $55 \%$ of patients with ischemic cardiomyopathy [116-119]. Studies have indicated that $\beta_{1}$ AR-AAb exert diverse allosteric effects, ranging from inhibitory to agonistpromoting activities, and that presence of $\beta_{1} \mathrm{AR}-\mathrm{AAb}$ negatively impacts LV function [116, 120], albeit there are contradictory reports. Among DCM patients, presence of activating $\beta_{1}$ AR-AAb was associated with severe ventricular dysfunction, higher risk of ventricular tachyarrhythmias and sudden cardiac death, and hence might be involved in the progression of DCM [117, 121]. In a clinical study consisting of 2,062 patients diagnosed with chronic HF due to DCM or ischemic cardiomyopathy, 379 (21.6\%) cases died during a 36-month follow-up period. Whereas patients with positive $\beta_{1}$ AR-AAb had comparable fatality due to non-arrhythmic causes, their risk of mortality in the form of sudden cardiac death was markedly higher (hazard ratio $=4.5$ for DCM, HR $=3.75$ for ischemic cardiomyopathy) [122]. $\beta_{1}$ AR-AAb may become undetectable following implantation of LV assistant device or anti-HF therapy.

Whereas the significance for the presence of $\beta A R-A A b$ remains partially understood, studies have shown that a subset of $\beta A R$-AAb may exert $\beta$-agonist-like activity. Binding of activating-AAb to the second extracellular loop of $\beta_{1} A R$ effectively and persistently activates downstream signaling pathways involving cAMP/PKA or p38MAPK [116, 120]. simulating prolonged activation of $\beta_{1} A R$ by catecholamines. $\beta_{1}$ AR-AAb may mediate apoptosis, pathological remodelling, and $\beta_{1} A R$ desensitization and downregulation. In vitro 
studies have been undertaken to explore action of $\beta A R-A A b$. In inflammatory macrophage-like cells, treatment with $\beta_{1}$ AR-AAb stimulated TNF- $\alpha$ expression and secretion, effect that was blocked by the selective $\beta_{1}$-antagonist metoprolol and partially by the PKA inhibitor H89 [123]. In cultured fibroblasts, use of $\beta_{1} A R-A A b$ obtained from patients with heart disease stimulated cell proliferation [120]. Presence of $\beta_{2} \mathrm{AR}-\mathrm{AAb}$ in patients with $\mathrm{HF}$ has also been reported [124]. A higher ratio of $\beta_{1} A R-A A b / \beta_{2} A R-A A b$ was associated with greater risk of worsening HF implying a potential of cardioprotection of $\beta_{2} A R-A A b$. Similar to $\beta_{1} A R-A A b, \beta_{2} A R-A A b$ could bind to and activate $\beta_{2} A R$. Cao et al. [124] furthered this finding by showing anti-apoptotic property of $\beta_{2} \mathrm{AR}-\mathrm{AAb}$ in cultured cardiomyocytes challenged with $\beta_{1}$ AR-AAb and also in mice treated with the anti-cancer drug doxorubicin.

Limited number of clinical studies have indicated beneficial effect from $\beta$-blocking therapy in patients with positive AAb [116]. Recently, $\beta_{1}$ AR-AAb-targeted therapies have received increasing interest. Therapies for immuneabsorption and neutralizing (e.g. using small peptides) or oligonucleotides of RNA- or DNA-like aptamers, that bind with high affinity to and neutralize AAb from $\beta_{1}$ AR-binding and facilitating clearance [116]. These therapies have been tested in preclinical models of cardiomyopathy or human HF patients with results showing effectiveness in removing $\beta_{1}$ AR-AAb. Recent studies have shown that $\beta_{1}$ AR-AAb-targeted therapies improved LVEF, NYHA (New York Heart Association) HF class or 6MWD (6-min walking distance), and lowed BNP level [116]. However, long-term effects remain to be obtained from large-scale trials. Nonetheless, $\beta_{1} \mathrm{AR}-\mathrm{AAb}$ have the potential to be novel therapeutic target for HF patients who are $\beta_{1}$ AR-AAb-positive.

\section{Sympatho- $\beta$-adrenergic signaling in immune cells}

Cross-talk exists between the SNS and the immune system, forming an important limb of the SNS to integrate body function and maintain homeostasis. Under conditions of inflammation or organ injury, sympathetic nerve firing rates increase leading to release of catecholamines in tissues such as born marrow, the spleen and lymphatic notes, and activation of $\beta A R$ in immune cells thereby modulating immune responses at a desired extent.

Recent studies have established that the SNS-BAR system regulates bone marrow-dwelled progenitors or immune cells to maintain homeostasis of immune system in physiology and to govern immune responses following pathological stimuli. Subtypes of $\beta A R$ are expressed in different immune cells derived from hematopoietic cells. $\beta_{3} \mathrm{AR}$ are restricted to bone marrow stromal cells, whereas $\beta_{2}$ ARs are highly expressed in hematopoietic and the stromal progenitor cells [125]. Sympathetic nerve fibers release NE that activates $\beta_{3} \mathrm{AR}$ of bone marrow niche cells to form upstream hematopoietic stem cells, followed by release of these cells into the blood circulation (Figure 4). With chronic stress, there is increased proliferation of these most primitive hematopoietic progenitors resulting in elevated levels of disease-promoting inflammatory leukocytes (Figure 4) [126-128]. In response to acute cardiovascular stress, like MI or stroke, numbers of neutrophils and monocytes harboured in the bone marrow increased within 2-3 days due to hyper-proliferation of specific myeloid progenitor cells, event associated with increased circulating counts of monocytes and neutrophils $[129,130]$. Nahrendorf and colleagues investigated kinetics of myocardial macrophages that contributes to cardiac remodelling in mice with chronic MI (eight weeks) and HF, and observed monocytosis as well as a 3-fold increase in myocardial macrophages [131]. In addition to resident macrophages, an important source of myocardial macrophages comes from the bone marrow hematopoietic stem and progenitor cells that displayed hyper-proliferation in animals with HF relative to controls. Sager et al. [131] observed that relative to control mice, NE level in bone marrow was 2-fold higher in HF, which was accompanied with enhanced release of these cells into blood circulation, splenic retention and proliferation, and myocardial recruitment. Thus, in mice with HF, higher sympathetic tone to bone marrow facilitate proliferation of bone marrow hematopoietic progenitor cells through activation of $\beta_{3} \mathrm{AR}$ (Figure 4), which leads to monocytosis and higher tissue density of monocytes like the spleen. These monocytes from the bone marrow and spleen then infiltrate the myocardium contributing to cardiac macrophages pool [131]. This finding bears therapeutic implications given that inhibiting monocyte recruitment would limit ventricular remodeling.

$\beta_{2} A R$ are the major $\beta A R$ subtype of bone marrowderived immune cells and play a vital role in neuronal regulation of inflammatory responses. Many earlier studies, largely in the in vitro setting, reported immunosuppressive action of $\beta_{2} A R$ stimulation. Lamkin et al. [132] studied gene patterns in human macrophages, and found that $\beta_{2} \mathrm{AR}$ stimulation induced a transcriptome typical of anti-inflammatory M2-pattern, together with suppression of pro-inflammatory M1-related genes. However, there is also report for $\beta_{2} A R$ signaling synergistically interacts with inflammatory stimuli (i.e. Toll-like receptor activators like lipopolysaccharide or phorbol myristate acetate) leading to activation of immune cells. Studies that carried out in vivo 


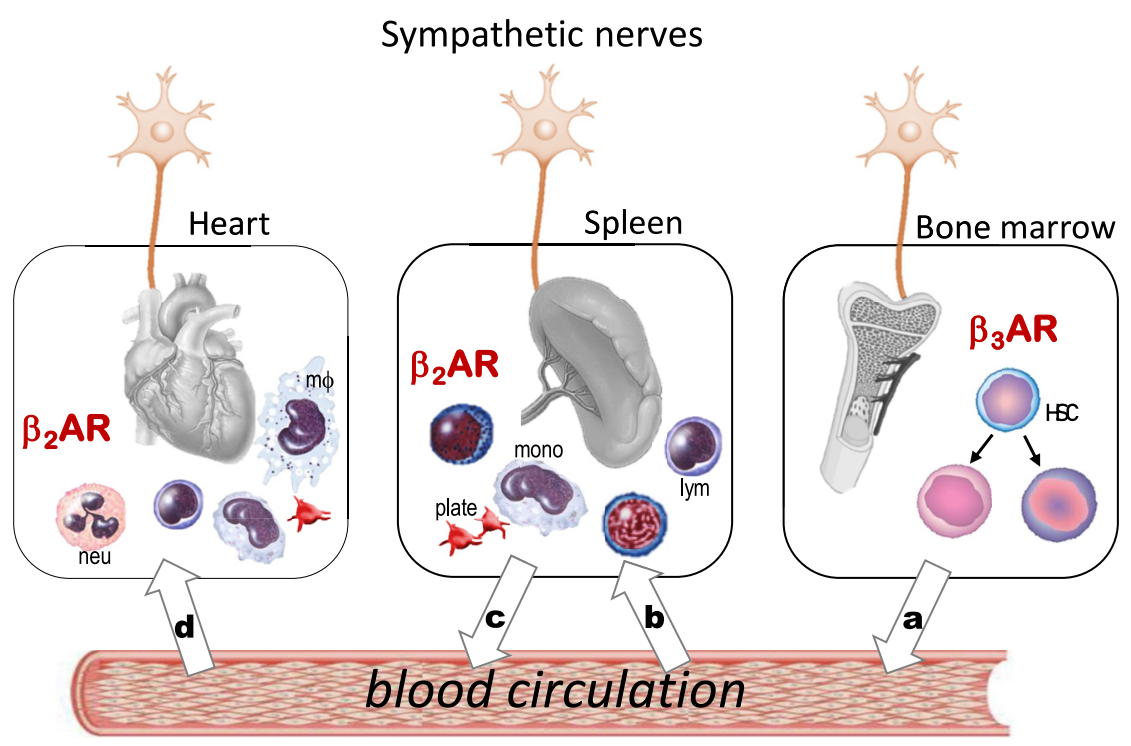

Figure 4: Sympathetic innervation of bone marrow and immune organs and $\beta A R$-mediated regulation of hematopoietic cells and immune cells. Sympathetic nerves, which innervate bones, can penetrate into the bone marrow compartment, where hematopoietic stem cells and progenitor cells (HSC) reside as specific niches. Catecholamines released by sympathetic varicosities activate hematopoiesis by stimulating $\beta_{3} A R$ in HSCs thereby promoting bone marrow cell differentiation, proliferation and egression of cells into blood circulation (a). After departing bone marrow, circulating immune cells relocate in immune organs like the spleen or lymph notes (b), where cells proliferate and mature and, upon sympathetic drive, depart immune organs into circulation (c). Circulating immune cells including monocytes (mono), lymphocytes (lym) and neutrophils (neu) then infiltrate the diseased myocardium (d) and promote regional inflammation. Immune cells are equipped mainly with $\beta_{2}$ ARs that regulate innate or acquired immunity, lymphocyte homing, immune cell maturation and expression of cytokines/chemokines. $m \phi$ : macrophages; plate: platelet.

have provided evidence for $\beta_{2} \mathrm{AR}$-mediated immuneenhancement [126, 133]. In mice with acute MI, Grisanti et al. [126] demonstrated that $\beta_{2} \mathrm{AR}$-mediated activation of immune cells is critical in regulating inflammatory-fibrotic healing. In mice depleted of $\beta_{2} A R$ gene and subjected to MI, inflammatory infiltration into the infarcted myocardium was blunted together with retention of immune cells within the spleen, changes associated with a markedly increased mortality (100\% vs. $20 \%$ in control mice) due largely to cardiac rupture as a consequence of impaired healing. In contrast, mice with bone marrow cell-specific depletion of $\beta_{1} \mathrm{AR}$ or $\beta_{3} \mathrm{AR}$ only showed insignificant change in the mortality. In mice with TAC-induced pressure overload, renal sympatho- $\beta_{2} \mathrm{AR}$ activation stimulated secretion of a cytokine CSF2 (colony stimulating factor 2), which is potent in activating monocytes or macrophages resided in the stressed myocardium [134]. Thus, the SNS- $\beta_{2}$ AR involves in the heart-kidney interplay contributing to the adaptation to hemodynamic stress (Figure 4).

The spleen stores a large number of immune cells as well as platelets that could be mobilized upon acute stress or sustained sympathetic activation, contributing to inflammatory response $[130,135]$. Following acute MI, circulating platelets undergo dynamic changes in size and activity $[106,136]$. In mice subjected to acute MI, we observed release of splenic platelets into blood circulation contributing to the increased platelet size, plateletmonocyte conjugation, and myocardial accumulation of platelets, changes that are highly pro-inflammatory. Such cardio-splenic response can be abolished by the angiotensin-converting enzyme inhibitor perindopril and $\beta$-antagonist atenolol [135], implying that elevated levels of Angiotensin-II and NE promote splenic release of immune cells and platelets (Figure 4). Clinical studies have also suggested that conditions associated with sympathetic activation, such as intense exercise or administration of catecholamines, induce splenic release of platelets. Conversely, sympatho- $\beta A R$ activation leads to shrink in splenic size and increase in circulating level of certain immune cell types. Thus, in the setting of $\mathrm{HF}$, enhanced sympathetic drive might induce splenic release of immune cells and platelets that subsequently promote inflammatory responses in the diseased heart. 


\section{$\beta A R$ signaling in fibroblasts}

Fibroblasts account for approximately $20 \%-30 \%$ of cardiac cell population with this number increasing substantially under pathological conditions. Over many years, research investigating the $\beta$-adrenergic mechanism in the setting of HF had been focused on cardiomyocytes. It has now been appreciated that events involving fibroblasts and inflammatory cells contribute significantly to the onset and development of HF. Fibroblasts are equipped mainly with $\beta_{2} \mathrm{AR}$ as well as downstream signaling molecules including AC, PKA, signaling scaffolding proteins like A-kinase anchoring proteins (AKAP) $\beta$-arrestins, EPAC and phosphodiesterases (PDE). Using FRET-based sensors, Grisan et al. [137] reported that cAMP signaling in cultured cardiac fibroblasts is mediated predominantly by $\beta_{2} \mathrm{AR}$. Whereas some earlier ex vivo studies reported that stimulation of $\beta_{2} \mathrm{AR}$ suppressed fibroblast proliferation and collagen synthesis, recent studies have revealed profibrotic actions mediated by $\beta_{2} \mathrm{AR}$ that involve fundamental cellular processes i.e. myofibroblast differentiation, proliferation, migration, and synthesis and release of extracellular matrix proteins [138]. For instance, in cultured cardiac fibroblasts, stimulation of $\beta_{2}$ ARs activates DNA synthesis, cell proliferation, expression of proinflammatory and fibrotic molecules like interleukin-6
(IL-6) $[30,138-142]$. One possible explanation to these contradictory findings comes from a study by Li et al. [143] using cultured fibroblasts from human cardiac biopsy of control subjects or HF patients, they observed that expression of $\beta$-arrestins was elevated that diminished $\beta$-agonist-mediated inhibition of fibroblast activity and collagen synthesis. Indeed, in cells with knockdown of $\beta$-arrestins, treatment with $\beta$-agonists inhibited fibroblast activity and collagen expression [143]. Enhanced $\beta$-arrestin signaling mediated a pro-fibrotic phenotype by promoting signaling that involves TGF- $\beta / \operatorname{Smad} 2 / 3$ and ERK1/2 [143]. Traveras et al. [144] studied mice with cardiac ischemia-reperfusion (IR) or fibroblasts prepared from biopsies of human patients with end-stage HF, and found that G $\beta y$-GRK2 signaling plays a key role in myocardial fibrogenesis. In addition, several studies have well documented that $\beta_{2} \mathrm{AR}$ stimulation of fibroblasts promotes expression and release of IL- 6 through signaling pathways involving Gs $\alpha / R E K 1 / 2$ [145], or p38MAPK [146]. There is also strong evidence for fibroblast-derived IL-6 in promoting cardiomyocyte hypertrophy [147]. However, the use of fibroblasts in culture, although allowing for dissection of molecular mechanisms in relation to fibrogenesis, is a very simplified model considering the in vitro environment where fibroblasts direct in contact with cardiomyocytes and indirectly influenced by factors released from cardiomyocytes.
A

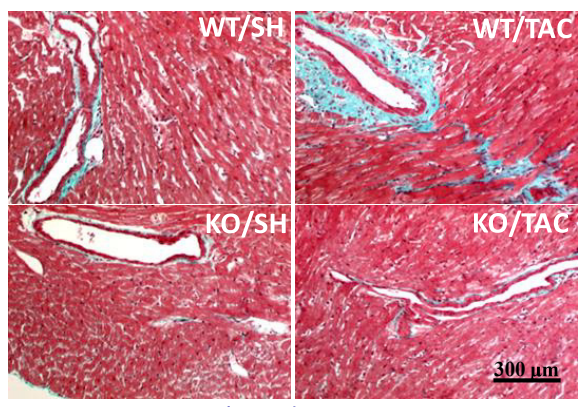

Masson's Trichrome

B

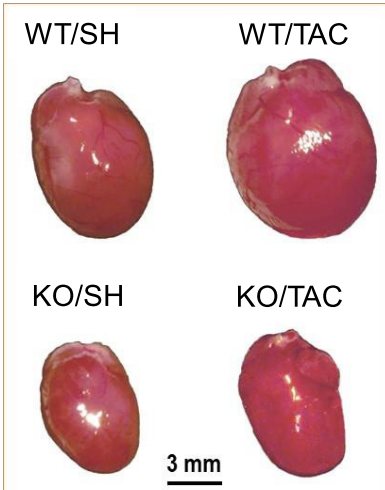

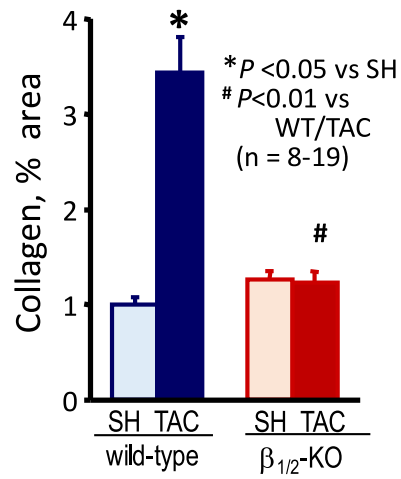

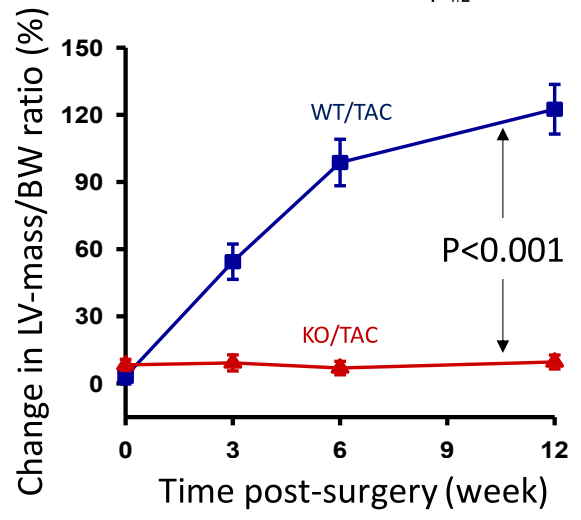

Figure 5: Cardiac phenotype of mice with dual deletion of $\beta_{1} A R$ and $\beta_{2} A R\left(\beta_{1 / 2}-K O\right)$ under conditions of chronic pressure overload. Following a 12-week period of pressure overload, wild-type (WT) control mice displayed significant cardiac interstitial fibrosis (A), hypertrophy (B) and signs of HF (e.g. pulmonary congestion, LV dilatation and dysfunction, atrial thrombus formation). All these changes, together with upregulation of pro-fibrotic and inflammatory genes in the stressed myocardium, were abolished in dual $\beta_{1 / 2}-\mathrm{KO}$ mice. These findings underscore an essential role of $\beta A R$ signaling in mediating fibrosis and hypertrophy induced by pressure overload [148]. $\mathrm{SH}$, sham-operation; TAC, transverse aorta constriction. Figure adopted from Kiriazis et al. with permission [148]. 
A pivotal role of $\beta A R$ in cardiac fibrosis signaling is suggested by our previous study on mice disrupted of both $\beta_{1^{-}}$and $\beta_{2}$-AR genes $\left(\beta_{1 / 2}-\mathrm{KO}\right) . \beta_{1 / 2}-\mathrm{KO}$ and control mice were subjected to TAC to induce chronic pressureoverload for up to 12 weeks. Significant myocardial interstitial fibrosis together with upregulated expression of fibrotic and inflammatory genes, and cardiac hypertrophy, whereas all being evident in control animals, were abolished in $\beta_{1 / 2}$-KO mice (Figure 5) [148]. Imaeda et al. recently generated mice with myofibroblast-restricted deletion of $\beta_{2} \mathrm{AR}$ and tested effects of treatment with ISO at a toxic dose $(50 \mathrm{mg} / \mathrm{kg} /$ day for two weeks). ISO-induced LV hypertrophy, dysfunction and fibrosis, seen in wildtype control mice, were largely prevented in KO mice [31]. The role of fibroblast $\beta$-adrenergic signalling in contributing to myocardial hypertrophy was further supported by the observation that mice with fibroblast-restricted overexpression of catalytic subunit of PKA developed cardiac hypertrophy [31]. Thus, these findings suggest that $\beta$ ARs not only in cardiomyocytes, but also in fibroblasts, play a central role in mediating cardiac hypertrophy and fibrosis in diseased settings.

Galectin-3 belongs to the lectin family and exerts profibrotic and pro-inflammatory actions through binding to numerous intracellular and membrane glycoproteins. Currently, galectin-3 is regarded as a useful biomarker for $\mathrm{HF}$ as well as a disease mediator. We explored whether BAR activation might lead to elevation of circulating galectin-3. Several murine models were studied including IR, ISO cardiotoxicity and $\beta_{2} \mathrm{AR}-\mathrm{TG}[64,66]$. In these models, circulating galectin-3 level was elevated in proportion to the increased galectin-3 content in the myocardium, and the cardiac source of circulating galectin-3 was further confirmed by the presence of transcardiac galectin-3 gradient [149], indicating spillover of cardiac galectin-3 into blood circulation [149]. Findings from these models differ from that in Mst1-TG mice with DCM [108], in which cardiac content of galectin-3 increased by 50 -folds, the highest among the models studied (7-18 folds), and yet circulating galectin-3 level was unchanged [149]. Interestingly, ISO treatment in Mst1-TG mice for 2 days markedly increased circulating levels of galectin-3, indicating that $\beta A R$ activation facilitates cardiac galectin-3 release into blood circulation. Importantly, $\beta A R$-mediated increase in both circulating and cardiac galectin-3 levels was reversed by the use of $\beta$-antagonists [31]. Significance of $\beta A R$-stimulated galectin-3 expression has been implicated by preclinical studies demonstrating that inhibition of galectin-3 by genetic or pharmacological means suppressed ISO-induced cardiac fibrosis and inflammation [114]. In a recent study, galectin-3 $\mathrm{KO}$ and wild-type control mice were subjected to chronic ISO administration. In control animals, ISO-induced increase in cardiac galectin-3 content (by 8 folds), LV hypertrophy, fibrosis and suppressed LV function, together with upregulation of a number of fibrotic and inflammatory genes [31]. All these phenotypes at molecular and global levels were abolished in galectin-3 KO mice, except for a similar degree of LV hypertrophy [31]. These findings call for clinical research to explore the influence of $\beta$-blockers on dynamic changes in circulating level of galectin-3 in relation to the overall therapeutic efficacy by $\beta$-blocking therapy.

Ample evidence has been accumulated for the interactions between cardiomyocytes and fibroblasts that are critical in fibrogenesis and pathological consequences [16]. We recently studied the role of $\beta A R$ in mediating such hetero-cellular interactions leading to fibrogenesis via galectin-3, $\mathrm{K}_{\mathrm{Ca}} 3.1$ (calcium-activated $\mathrm{K}^{+}$channel), and junctional protein connexin-43 ( $\mathrm{Cx} 43)$ (Figure 6) [150, 151]. Specifically, stimulation of cardiomyocyte $\beta A R$ enhances expression of galectin-3, which induces $\mathrm{K}_{\mathrm{Ca}} 3.1$ expression in non-cardiomyocyte cells. In addition to further inducing galectin-3 expression, $\mathrm{K}_{\mathrm{Ca}} 3.1$ enhances $\mathrm{Ca}^{2+}$ influx via transient receptor potential (TRP) channels leading to activation of inflammatory cells and fibroblasts (Figure 6A) [150]. In mouse models of ISO-cardiotoxicity or $\beta_{2}$-TG, treatment with a $\mathrm{K}_{\mathrm{Ca}} 3.1$ inhibitor suppressed inflammation and fibrosis [150]. Cx are membrane proteins that are expressed in cardiomyocytes and fibroblasts and form hemichannels and gap junctions between cells. Zhang et al. [142] recently reported cell-type distinct regulation by $\beta A R$ of expression and localization of Cx43. Whilst $\beta_{2} A R$ stimulation upregulates expression of Cx43 in fibroblasts together with enhanced fibroblast activity, $\beta A R$ activation in cardiomyocyte downregulates Cx43 expression together with redistribution of $\mathrm{Cx} 43$ from interdisc to laterals (Figure 6B). Moreover, $\beta$ AR stimulation leads to formation of inflammasomes that cleavage inactive pre-IL-18 to active IL-18, which further augments $\mathrm{Cx} 43$ expression in fibroblasts (Figure 6B) [142]. These changes are expected to increase the probability of formation of Gapjunctions between heterogeneous cells (i.e. cardiomyocytes and fibroblasts), changes in favour of electrophysiological disturbance and arrhythmogenesis [16, 152]. Gap-junction mediated coupling of adjacent fibroblasts has also been shown to promote fibroblast differentiation, proliferation and migration, as well as facilitate inflammatory-fibrotic process $[153,154]$. 
A
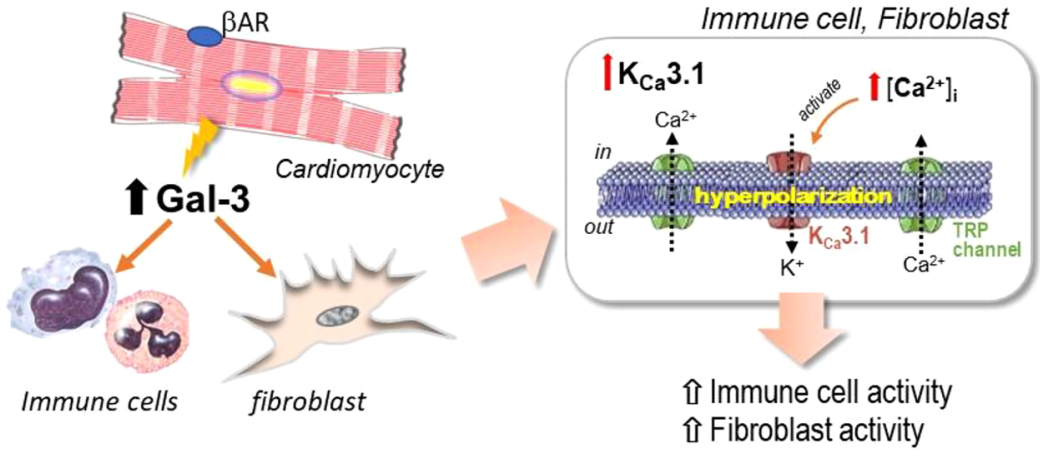

B Normal

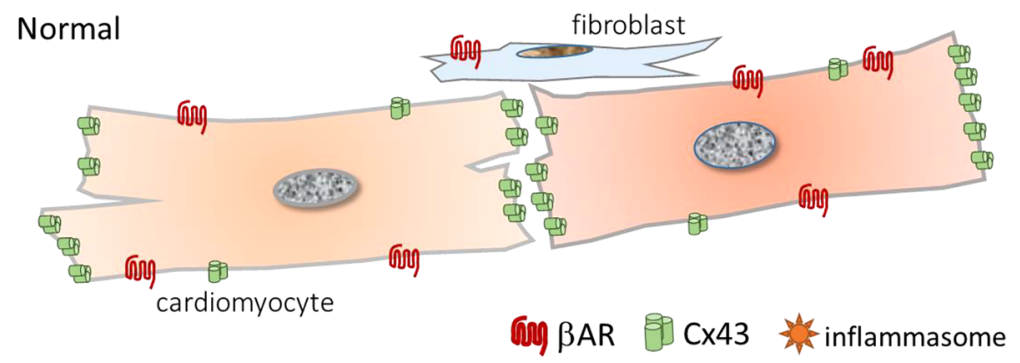

$\beta A R$ over-activation

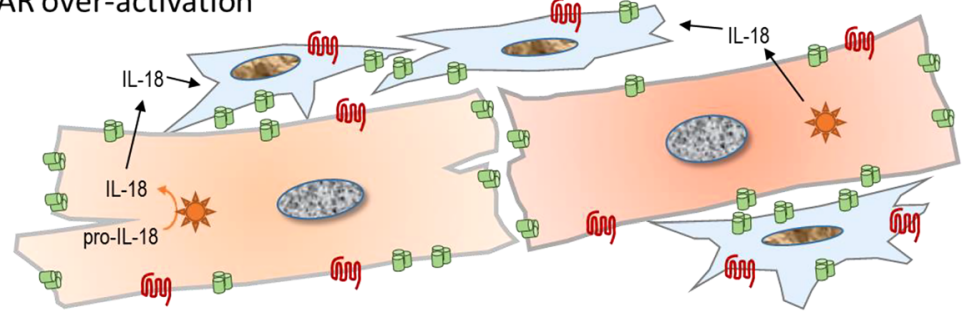

Figure 6: Schematic diagrams depicting $\beta A R$-mediated heterogeneous cell interactions promoting cardiac fibrosis. (A) Stimulation of $\beta A R$ in cardiomyocytes induces expression and release of galectin3 (Gal-3), which in turn activates expression of intermediate-conductance $\mathrm{Ca}^{2+}$ activated $\mathrm{K}^{+}\left(\mathrm{K}_{\mathrm{Ca}} 3.1\right)$ channels in fibroblasts or immune cells. Activity of $\mathrm{K}_{\mathrm{Ca}} 3.1$ channels leads to membrane hyperpolarization and subsequent $\mathrm{Ca}^{2+}$ influx via transient receptor potential (TRP) cation channels by which fibroblasts or inflammatory cells are activated [150]. (B) $\beta A R$ activation in cardiomyocytes suppressed $\mathrm{C} \times 43$ expression and shifted $\mathrm{C} \times 43$ localization from interdisc to lateral sides of cells. Cx43 expression in fibroblasts is upregulated via direct activation of $\beta_{2} A R / P K A$ signaling cascade [142]. Besides, interleukin-18 (IL-18) released via $\beta A R$-mediated formation of inflammasomes in cardiomyocytes further upregulates $\mathrm{Cx} 43$ expression in fibroblasts [142]. These changes would favour the probability of cardiomyocytefibroblast coupling via Gap-junctions with consequent electrophysiological instability $[16,152,154]$, or activation of coupled fibroblasts [153].

\section{Potential role of cardiac $\alpha_{1} A R$ in HF}

It is estimated that $\alpha_{1} \mathrm{ARs}$, mainly $\alpha_{1 \mathrm{~A}} \mathrm{AR}$ and $\alpha_{1 \mathrm{~B}} \mathrm{AR}$ subtypes, account for approximately $10 \%$ of total AR in the heart [155]. However, relative to $\beta A R$, cardiac $\alpha_{1} A R$ has been much less investigated. Studies using a diversity of approaches have shown that activation of $\alpha_{1 \mathrm{~B}} \mathrm{AR}$ in the heart subjected to disease insults leads to adverse consequences [155-157]. Under conditions of chronic pressure overload, we observed in $\alpha_{1 \mathrm{~B}}$-TG mice more severe hypertrophy, fibrosis and HF relative to non-TG littermates, indicating adverse effect of $\alpha_{1 \mathrm{~B}} \mathrm{AR}$ in this pathological setting [158]. In contrast, accumulating evidence indicates that stimulation of $\alpha_{1 \mathrm{~A}} \mathrm{AR}$ holds promise to be developed for treatment of HF. Mice with cardiomyocyte specific knockout of both $\alpha_{1 \mathrm{~A}} \mathrm{AR}$ and $\alpha_{1 \mathrm{~B}} \mathrm{AR}$, showed poor tolerance to TAC challenge with significant apoptosis, LV dilatation and premature deaths due to HF [159]. Further investigation indicated that it was loss of $\alpha_{1 \mathrm{~A}} \mathrm{AR}$, but not $\alpha_{1 \mathrm{~B}} \mathrm{AR}$, that was responsible for cardiac maladaptation. Huang et al. [160] studied cardiomyocytes with selective depletion of $\alpha_{1 \mathrm{~A}} \mathrm{AR}$, and observed an increased cell death due to apoptosis or necrosis induced by stimuli of NE, doxorubicin or $\mathrm{H}_{2} \mathrm{O}_{2}$.

Several studies have addressed the downstream signaling mechanisms responsible for the cardioprotective action of $\alpha_{1 \mathrm{~A}} \mathrm{AR}$. Whilst treatment with $\alpha_{1 \mathrm{~A}} \mathrm{AR}$ agonist (A61603) provides cardiac protection in wile-type mice subjected to TAC, such effect of $\alpha_{1 \mathrm{~A}}$-agonist was lost in mice with cardiac expression of inactive mutant $\alpha_{1 \mathrm{~A}} \mathrm{AR}$ that prevents Gq-protein coupling [161]. Cardiac protection conferred by $\alpha_{1 \mathrm{~A}} \mathrm{AR}$ is mediated by diverse Gq-dependent signaling that involves $\mathrm{PKC} \delta /$ glucose transporter-1/4 to promote metabolism [162], Gq/ERK to antagonize apo ptosis [161], or pro-angiogenesis occurring post-MI [163]. Cardioprotection by enhanced $\alpha_{1 \mathrm{~A}} \mathrm{AR}$ signaling is further supported by studies using a mouse model with cardiac overexpression of $\alpha_{1 \mathrm{~A}} \mathrm{ARs}\left(\alpha_{1 \mathrm{~A}}\right.$-TG). $\alpha_{1 \mathrm{~A}}$-TG mice displayed cardiac hyper-contractile function without adverse myocardial hypertrophy or fibrosis [164]. Using $\alpha_{1 \mathrm{~A}}$-TG and non-TG mice subjected to chronic MI or pressure overload (TAC), studies have shown that genetic $\alpha_{1 \mathrm{~A}}$-AR activation preserved 
LV function and reduced HF death under both disease settings $[156,163,165]$. Similar cardioprotection by treatment with a selective $\alpha_{1 A}$-agonist was observed in animals treated with anti-cancer drug doxorubicin [166, 167]. In cardiac biopsy samples from patients without or with cardiomyopathy and $\mathrm{HF}$, all three subtypes of $\alpha_{1} \mathrm{AR}$ were expressed at mRNA level $[168,169]$, only $\alpha_{1 \mathrm{~A}} \mathrm{AR}$ and $\alpha_{1 \mathrm{~B}} \mathrm{ARs}$ were detectable at the protein level (60\% $\left.\alpha_{1 \mathrm{~B}} \mathrm{ARs}\right)$ which was maintained in the failing myocardium, implying that $\alpha_{1}$ ARs do not undergo downregulation $[168,169]$. We also showed, in mice with chronic pressure-overload that expression of $\alpha_{1 \mathrm{~A}} \mathrm{AR}$ in hypertrophic myocardium was unchanged [158]. These findings are in keeping with another report showing that in myocardial samples from HF patients, $\alpha_{1 A} A R$ mediated positive inotropy remains intact [170]. The mechanism of the inotropic action, seen in $\alpha_{1 \mathrm{~A}}$-TG mice or use of selective agonist, is only partially understood but involves increased $\mathrm{Ca}^{2+}$ sensitivity of contractile apparatus following phosphorylation of contractile regulatory proteins by RhoA/ ROCK kinases, and elevated intracellular $\mathrm{Ca}^{2+}$ signaling [171]. The increased $\mathrm{Ca}^{2+}$ entry by $\alpha_{1 \mathrm{~A}} \mathrm{AR}$ activation is achieved through transient receptor potential channels (TRPC6) that relocate from plasma to sarcolemma upon activation of $\alpha_{1 \mathrm{~A}} \mathrm{AR} / \mathrm{Gq} / \mathrm{PLC} \beta /$ diacylglycerol signaling [172].

\section{Changes in presynaptic regulation of neurotransmission by $\alpha_{2} A R$}

Sympathetic neuronal release of NE is controlled by diverse presynaptic receptors that mediate either stimulatory (e.g. $\beta_{2} A R$, angiotensin $A_{1} R$ ) or inhibitory regulation (e.g. $\alpha_{2} \mathrm{AR}$, dopaminergic $\mathrm{DA} 2$, muscarinic $\mathrm{M} 2$, purinergic $\mathrm{A} 1$, NPY-receptor). Of them, $\alpha_{2} \mathrm{AR}$ mediates the most potent suppression of NE exocytosis, by which $\alpha_{2} \mathrm{AR}$ determines the extent of stimulation of postsynaptic $\beta A R$ or $\alpha A R[173,174]$. Among three subtypes $\left(\alpha_{2 \mathrm{~A}}, \alpha_{2 \mathrm{~B}}\right.$ and $\left.\alpha_{2 \mathrm{C}}\right), \alpha_{2 \mathrm{~A}} \mathrm{AR}$ and $\alpha_{2 \mathrm{C}} \mathrm{AR}$ are functionally important. In mice deficient of $\alpha_{2 A} A R\left(\alpha_{2 A^{-}}\right.$ $\mathrm{KO})$, loss of presynaptic suppression of NE release results in higher baseline heart rate (by 47\%), lower NE content (by 57\%), and lower $\beta A R$ density (by 26\%) [175], changes similar to that seen in the human failing heart. Under chronic pressure overload by TAC, Hein's group documented, in $\alpha_{2 A^{-}}$ $\mathrm{KO}$ and $\alpha_{2 \mathrm{C}}$-KO mice, increased mortality due to HF, more severe LV hypertrophy and fibrosis, poorer LV function, and elevated levels of circulating catecholamines [176]. In human studies, facilitatory regulation of NE release by presynaptic $\beta_{2} \mathrm{AR}$ is not evident, but inhibitory regulation by $\alpha_{2 \mathrm{C}} \mathrm{AR}$ is potent $[177,178]$. The $\alpha_{2 C}$ AR deletion variant with loss of four amino acids in the third intracellular domain $322-325$, is commonly in the population $[179,180]$. Such loss-of-function polymorphism significantly impairs the signal transduction of $\alpha_{2 C} A R$ and presynaptic inhibition of NE release. Importantly, Brede et al. [176] showed, for the first time, that in chronic $\mathrm{HF}$ patients who had the $\alpha_{2 \mathrm{C}} \mathrm{AR}$ deletion variant exhibited more severe HF relative to patients with intact $\alpha_{2 C} A R$. However, down-regulation of presynaptic $\alpha_{2 C} A R$ in cardiac sympathetic nerves and the adrenal gland has been noticed in HF patients [88, 177], which might explain the lack of significant change in cardiac NE kinetics in patients with the $\alpha_{2 \mathrm{C}} \mathrm{AR}$ deletion variant [178].

Several studies have implicated the prognostic significance of $\alpha_{2 C} A R$ polymorphism in patients with HF. Small et al. [180] reported that the $\alpha_{2 \mathrm{C}} \mathrm{AR}$ deletion variant is more common in blacks than whites ( $61 \%$ vs. $41 \%)$, which might contribute to a poorer prognosis in blacks than whites with HF. However, in a study on 345 patients with DCM and a mean follow-up period of 4.9 years, patients carrying the $\alpha_{2 \mathrm{C}} \mathrm{AR}$ deletion variant had lower risk for total adverse event rates $(-83 \%)$ or death rate $(-87 \%)$ [179]. This seemingly contradictory finding might be due to the common use in this patient cohort of $\beta_{1}$-antagonist, that spares potentially protective $\alpha_{1}$ AR or $\beta_{2} A R$. Potential drug intervention of presynaptic receptors has recently been explored. Using the rat model of $\mathrm{MI}$, treatment with CHF-1024 as an agonist for $\alpha_{2} \mathrm{AR}$ and DA2, dosedependently reduced cardiac release of NE and expression of TNF $\alpha$, effects accompanied by alleviated myocardial damage and improved LV function [181], indicating cardioprotection via blunted sympathetic surge post-MI. In a randomised clinical trial on 1,000 patients with severe $\mathrm{HF}$, treatment with nolomirole, an agonist of $\alpha_{2} \mathrm{AR}$ and DA2, had no benefits in terms of HF-hospitalization or survival, nor to alter heart rate and blood pressure [182]. In another study on HF patients and controls, significance of the $\alpha_{2 \mathrm{C}} \mathrm{AR}$ deletion variant and $\beta_{1} \mathrm{AR}$ within Gs-binding domain high-function-variant (Arg398) relative wild-type (Gly398) was investigated [180]. In black subjects, risk of HF increased by 5.6-fold with the $\alpha_{2 C} A R$ only, but by 10.1fold in subjects carrying both $\alpha_{2 C} A R$ deletion variant and $\beta_{1}$ AR high-function-variant [180]. In a clinical trial on 1,040 HF patients testing the $\beta$-clocker bucindolol, which is also a sympatholytic agent, Aleong et al. [183] explored the impact of the $\alpha_{2 \mathrm{C}} \mathrm{AR}$ deletion variant on effect of bucindolol, and found that $\alpha_{2 C} A R$ wild-type patients respond to this drug with a pronounced sympatholytic effect, lower incidence of malignant ventricular tachyarrhythmias, and a better survival. In contrast, such effects of bucindolol were attenuated or completely lost in patients carrying the $\alpha_{2 C} \mathrm{AR}$ deletion variant. Collectively, the $\alpha_{2 \mathrm{C}} \mathrm{AR}$ deletion variant augments NE release, which is potentially 
detrimental to the diseased and failing heart. However, such influence is also subjected to modulation by $\beta_{1} \mathrm{AR}$ high- or low-function variants.

\section{Remodeling of cardiac sympathetic nerves}

In addition to the well-documented cardiac sympathetic overdrive and enhanced $\mathrm{NE}$ release, studies have revealed morphological and functional abnormalities of sympathetic nerves in the failing heart, likely as a combined consequence of sustained enhancement of sympathetic neuronal tone and altered retrograde signals from the myocardium $[8,10]$. A range of abnormalities of cardiac sympathetic nerves have been identified in the failing heart (Figure 7). First, numerous studies have reported lower sympathetic nerve density in the failing myocardium, suggesting loss of sympathetic neurons or axons [5, 42, 184], albeit there are reports of increased nerve density in hypertrophic or failing myocardium.

Second, earlier studies showed a partial NE depletion in the failing myocardium, which is attributable to long-term excessive NE release together with attenuation of both $\mathrm{NE}$ biosynthesis and NE reuptake (Figure 7) [10, 42, 185]. Backs et al. [186] observed in the rat with TAC-induced HF and significant cardiac remodelling, that whereas neuronal $\mathrm{NE}$ transporter (NET) mRNA level was unchanged in neurons localized at the left stellate ganglion, there was a $40 \%$ reduction in NET binding sites, change independent of nerve density. In varicosities, NE is transported through vesicular monoamine transporter (VMAT) back into vesicles for storage, or alternatively metabolised by monoamine oxidase (MAO) to form dihydroxyphenyl glycol (DOPEG) that can diffuse freely through sarcolemma membrane into circulation (Figure 7). Patients with HF showed greater cardiac spillover of DOPEG [8, 42], suggesting increased

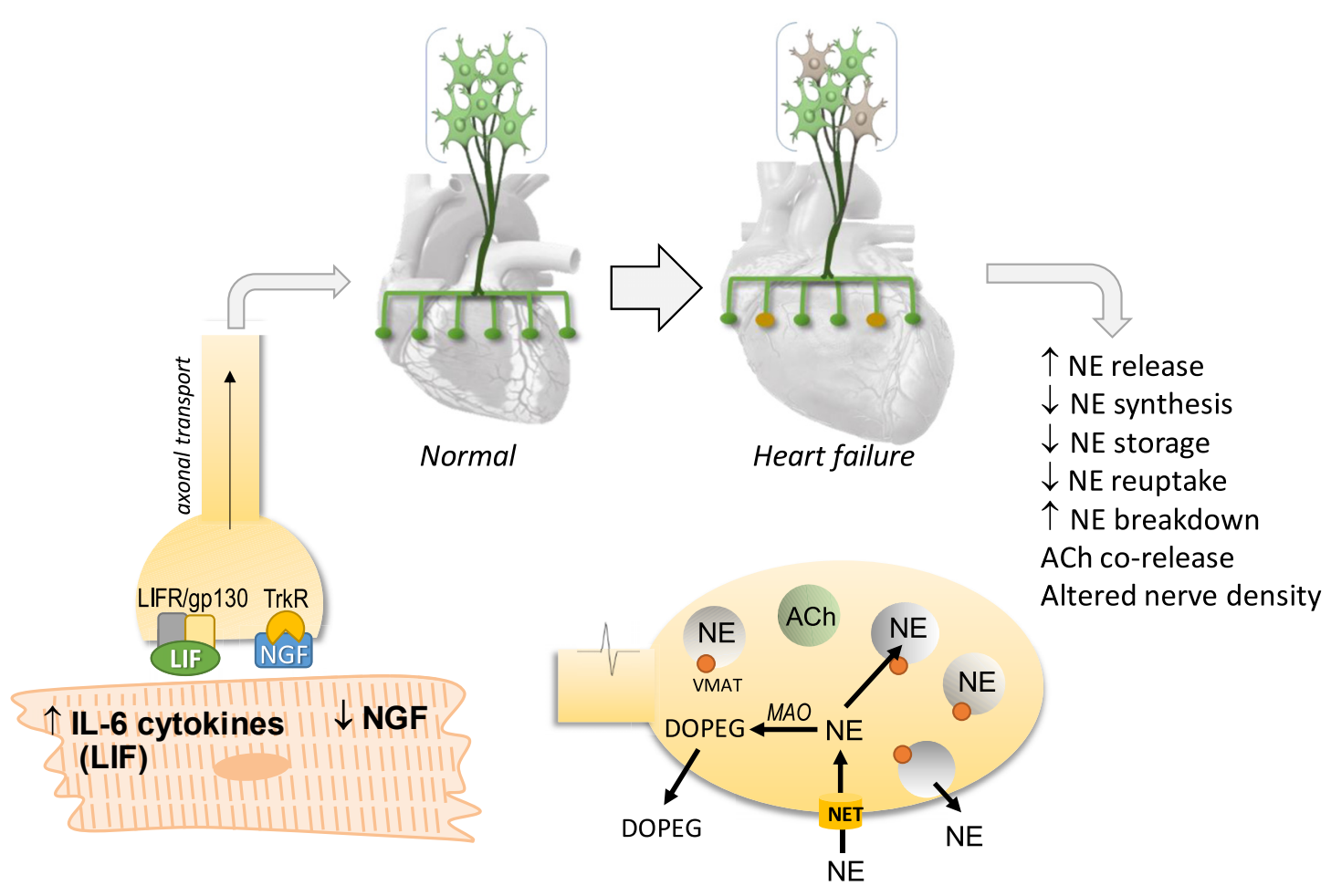

Figure 7: Remodeling of cardiac sympathetic nerves in the failing myocardium. Most likely due to chronic sympathetic hyperactivity, cardiac sympathetic nerves exhibit functional and phenotypic changes. Changes in sympathetic neurons consist of reduced expression of tyrosine hydroxylase (TH, a limiting enzyme of NE synthesis) and NE transporter (NET), and yet expression of choline acetyltransferase (ChAT) is induced in certain neurons. These changes, defined as neurotransmitter switching, are characteristic of neuronal "rejuvenation". The mechanism involves alterations of retrograde signaling of cardiomyocytes on neurons, notably upregulation of interleukin-6 (IL-6) family cytokines (e.g. leukaemia inhibitory factor, LIF) and down-regulation of nerve growth factor (NGF). LIF and NGF bind to respective receptors on the presynaptic membrane, undergo reverse-transportation to reach neuronal bodies, where they induce phenotypic changes. At varicosities, there are overt reduction in NE reuptake but increased NE breakdown by monoamine oxidase (MAO), which, together with excessive release and reduced biosynthesis, result in partial NE depletion. ACh: acetylcholine; DOPEG: 3,4-dihydroxyphenylethyl glycol; LIF-R: LIF receptor; TrkA: NGF-activated tyrosine kinase receptor; VMAT: vesicular monoamine transporter. 
NE breakdown. It remains unknown whether there is concomitant attenuation in the activity of VMAT in the failing heart that would exacerbate NE metabolism and depletion.

Third, sympathetic nerves undergo neurotransmitterswitching with phenotype changes (Figure 7) [187]. Expression of interleukin (IL)-6 cytokines is elevated in the failing myocardium or in cardiac cells upon $\beta A R$ stimulation $[141,188,189]$. Leukemia inhibitory factor (LIF) is a member of IL- 6 cytokine family and could regulate sympathetic neuronal plasticity through binding to its dualmolecule receptor LIF-receptor and gp130. Earlier studies in cultured sympathetic neurons revealed that LIF induced switch of neurotransmitters from NE to acetylcholine (ACh). Using the failing heart of salt-sensitive Dahl rats, Kanazawa et al. [187] reported an increased abundance of cholinergic neurons, including peripheral axons as well as neuronal bodies, that express markers like choline acetyl-transferase (ChAT) and vesicular ACh transporter (VAChT). This finding was further confirmed by another study on samples of LV and stellate ganglia from autopsied HF patients showing neuronal marker switching from tyrosine hydroxylase $\left(\mathrm{TH}^{+}\right.$, i.e. noradrenergic) to cholineacetyltransferase ( $\mathrm{ChAT}^{+}$, i.e. cholinergic) [187]. Whereas the significance of such cholinergic trans-differentiation of cardiac sympathetic nerves remains to be fully illustrated, this likely represents an adaptive change to protect against cardiotoxicity by excessive sympathetic drive, akin to that of $\beta_{1}$ AR-downregulation and desensitization or alternatively by the use of $\beta$-blockers. Together with reasons like excessive NE release, reduced NE synthesis and faulty NE reuptake $[186,190]$, such neurotransmitter switching adds to an alternative mechanism responsible for the partial depletion of NE content in the failing heart (Figure 7). Changes in neurotransmitter identity is a common feature during neuronal development. Kimura et al. [185] proposed that neurotransmitter switching as well as other loss-of-function changes (e.g. reduction in NE uptake, lower NE content, suppressed NE synthesis) are "sympathetic rejuvenation", which is characterized by expression of markers of immature neurons and likely driven by LIF and cardiotrophin-1. Thus, the augmented expression of IL- 6 family cytokines in the failing heart or under $\beta$-adrenergic stimulation [30,139, 189, 191], induces functional loss of sympathetic nerves together with neurotransmitter plasticity, that might impact disease compensation and development. Recent studies have shown that after MI, cardiac sympathetic nerves undergo transient neurotransmitter switching, evidenced by expression of ChAT in adrenergic neurons and, upon stimulation, simultaneous release of $\mathrm{NE}$ and $\mathrm{ACh}$ within the first two weeks post-MI [192, 193]. There is evidence for ACh co-released with NE counteracting the proarrhythmic electrophysiological property induced by $\mathrm{NE}$, such as heterogeneity of action potential duration crossing the infarcted heart [192, 193]. By testing effects of different $\mathrm{Ca}^{2+}$-channel blockers in HF patients, a recent clinical study revealed switching of neuronal $\mathrm{Ca}^{2+}$ channels from $\mathrm{N}$-type (restricted to peripheral nerves) to L-type (central nerves) [194].

One important mechanism for the abnormal cardiac sympathetic nerves is altered expression in the failing myocardium of neurotrophic factors, most notably nerve growth factor (NGF). Sympathetic neuronal function and innervation density are regulated by target organ-derived neurotrophic factors, which mediate retrograde signals essential for the development and differentiation of neurons and acquisition of neuronal properties [185]. These neurotrophic factors bind to respective receptors localized at presynaptic membrane (e.g. tyrosine kinase receptor, TrKA, for NGF), and then undergo retrograde axonal transportation to reach the neuronal body where they regulate plasticity, function and phenotype of sympathetic neurons (Figure 7). We studied cross-cardiac gradient of NGF concentration by sampling arterial and coronary sinus blood from patients with HF due to DCM or ischemic cardiomyopathy (average LVEF 17\%, NYHA class 3.1), as well as NGF expression in heart tissues from rats with chronic MI-induced HF or in cultured cardiomyocytes stimulated with NE [195]. In HF patients, blood concentration of NGF and trans-cardiac NGF gradient were dramatically lower relative to healthy controls, implying reduced NGF production in the failing myocardium. This was confirmed by reduction in NGF expression at mRNA $(-40 \%)$ and protein $(-24 \%)$ levels in rat failing hearts. Furthermore, in cultured cardiomyocytes, expression of NGF was inhibited by treatment with NE [195]. Similar findings have been reported by subsequent studies on different animal models of HF or NE stimulation. Kimura et al. [196] reported that in rats received chronic NE infusion, animals showed cardiac downregulation of NGF expression and loss of sympathetic nerve fibers. In dogs with an 8-week period of rapid-pacing and HF, expression level of NGF in the myocardium was lower at mRNA and protein levels, together with downregulated expression by neurons of NGF-receptor TrKA [197]. These changes were in parallel with loss of sympathetic nerve densities and reduced activity of $\mathrm{TH}$, the rate-limiting enzyme for $\mathrm{NE}$ biosynthesis [197]. In rats with TAC and HF, animals showed reduction in both NGF expression and NE reuptake by NET, and a partial NE depletion [198]. Importantly, there was a report showing that in rats with HF, NGF injection 
into the left stellate ganglion restored NET expression and $\mathrm{NE}$ content, changes accompanied by improvement of LVEF [198]. This finding is in keeping with our previous study in mice with cardiac overexpression of NGF, in which we observed cardiac hyper-innervation, higher tissue NE content and enhanced NE reuptake, but with preservation of $\beta A R$-response and LV geometry and function, likely due to concomitant enhancement of NE reuptake [199]. However, there is discrepancy regarding NGF expression levels in hypertrophic and failing hearts. In myocardial tissues from human subjects with ischemic heart disease, there was 2.5-fold increase in NGF level that was associated with increased sympathetic axon diameters. Similar morphological changes were also observed in spontaneously hypertensive rats or dogs with ischemic cardiomyopathy [200]. The reason(s) for such discrepancy regarding NGF level in diseased myocardium remain unclear, but influences such as aetiologies, diversity of cardiac sampling regions or disease stage, cannot be excluded. Indeed, NGF expression is known to be differentially regulated by factors relevant to heart disease, for instance, calcineurin-NFAT downregulates whilst endothelin-1 (ET-1) upregulated NGF expression [185]. Collectively, these data indicate a dynamic and constant NGF expression in the heart and that dysregulation of neurotrophic action of NGF in the heart contribute to neuronal dysfunction irrespective of reduced or increased sympathetic densities in the hypertrophic or failing heart.

NPY is a neuropeptide of 36 amino acids, present in central nervous tissue and peripheral sympathetic nerves and, upon sympathetic activation, co-released with NE. Whilst earlier studies observed higher cardiac and circulating levels of NPY under conditions of cardiovascular stress (hypertension, MI, hypertrophy or HF) [201], a few recent studies have enriched our understanding on the role of NPY. In rats with acute MI, Huang et al. [202] observed a 3-4-fold increase in cardiac and plasma levels of NPY, albeit the expression level of NPY at the sympathetic ganglion was not determined. Interestingly, they showed that NPY-KO rats subjected to MI had smaller infarct size and lower level of cardiomyocyte apoptosis, evidence of cardioprotion [202]. In a recent study on patients with acute MI and by blood sampling from the coronary sinus, Kalla et al. [203] showed that in patients exhibited sustained VT or VF, NPY co-released with NE from the infarcted heart is pro-arrhythmic, even in the presence of $\beta$-antagonists. Kalla et al. [203] furthered this finding by studying perfused rat hearts subjected to the sympathetic stellate ganglion stimulation, which increased VF vulnerability even in the presence of the $\beta_{1}$-antagonist metoprolol. Elevated VF vulnerability was prevented with the use of Y1 receptor antagonist (BIBO3304) but induced by NPY infusion. Over several decades, the role of NPY in chronic HF remains unclear. Olujini et al. recently investigated the implication of coronary sinus NPY levels in relation to clinical outcomes of chronic HF patients [204]. In 105 patients with HF (mean LVEF 26\%), higher NPY levels in coronary sinus blood was associated with overall adverse cardiac events (death, HF hospitalization, requirement of heart transplantation or placement of cardiac assistant device, adjusted HR 9.3, $P<0.001$ ) [204]. Furthermore, Ajijola et al. [204] observed in stellate ganglion biopsy from chronic HF patients, lower NPY protein content but unchanged NPY mRNA level, indicating increase NPY release. Medzikovic et al. [205] observed that a nuclear receptor Nur77 was potent in inducing NPY expression, and they further showed that Nur77 gene deletion (Nur77-KO) or treatment with Y1-antagonist (BIBO3304) were beneficial in a model of drug-induced cardiomyopathy.

\section{Neuromodulation of the sympathetic nervous system by device-based interventions}

It is well established that central imbalance of the autonomic nervous system is a key component of HF pathophysiology [4, 206]. In this regard, sustained activation of the SNS together with suppression of the parasympathetic nervous system characterize clinical features of patients with HF. Advanced from the previous viewpoint of peripheral SNS abnormalities in HF [7], increasing number of studies have suggested central nervous abnormalities in HF subjects [4, 207]. Using several independent methodologies for clinical assessment of SNS activity, studies have revealed augmented sympathetic efferent firing rates, increased circulating level of catecholamines, and blunted baroreflex sensitivity or heart rate variability [11, 12]. Thus, HF could be a clinical condition in which abnormalities in the SNS is evident not only peripherally, but also centrally. The autonomic nervous activity is centrally regulated by processing numerous afferent inputs that are both inhibitory or excitatory in nature. In this regard, the pioneer studies by Esler and colleagues on renal sympathetic denervation (RSD) for treatment of resistant hypertension have re-directed research attention into the area of neuromodulation by device-based interventions to achieve centrally resetting of the SNS activity in HF (Figure 8).

Studies have shown that neuromodulation is achievable through device-based interventions or pharmacology 


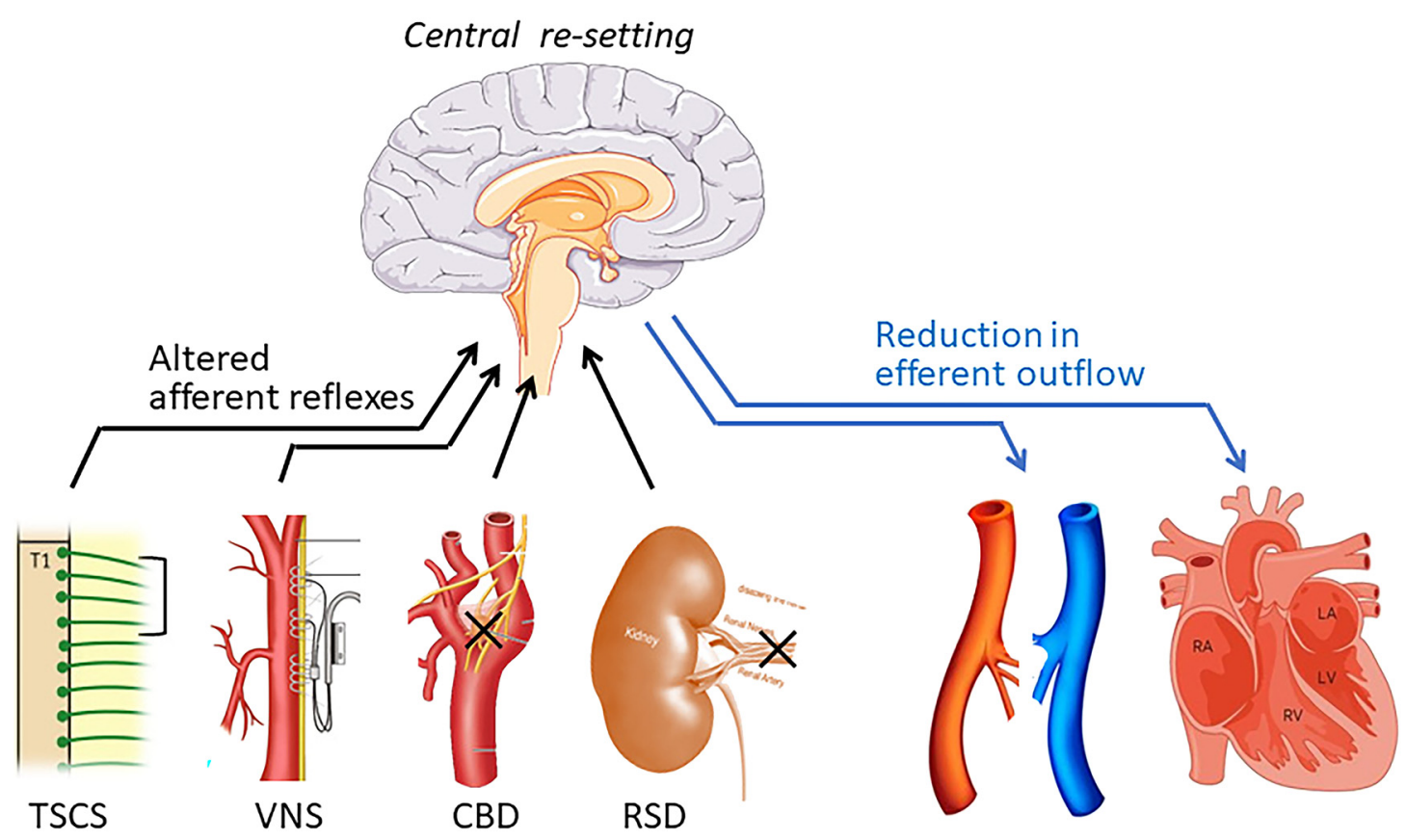

Figure 8: Neuromodulation with suppression of cardiovascular sympathetic nervous activity by device-based interventions. Increasing number of preclinical studies have shown that SNS activity could be suppressed through non-pharmacological device-based procedures, including thoracic spinal cord stimulation (TSCS), vagus nerve stimulation (VNS), carotid body denervation (CBD) or renal sympathetic denervation (RSD). Currently preclinical studies indicate that these interventions similarly induce central resetting, reduce cardiac sympathetic outflow and plasma NE levels, leading to cardioprotective actions. However, clinical studies on HF patients thus far could only replicate parts of these findings from large animal models with reasons to be explored.

means (Figure 8). Potential non-pharmacological therapeutic approaches include ganglionated plexus ablation, thoracic spinal cord stimulation (TSCS), carotid body denervation (CBD), renal sympathetic denervation (RSD) and cervical vagal nerve stimulation (VNS).

\section{Thoracic spinal cord stimulation (TSCS)}

The establishment of TSCS is based on the progress in the anatomy and physiology of the autonomic nervous system that regulates the heart [208]. Whereas the mechanism remains undefined, TSCS is usually applied to T1-T4 segments of the spinal vertebrate, and has been shown to limit arrhythmic events and improve cardiac function. In porcine models of HF due either to MI or rapid pacing, TSCS for a four-week period improved LV performance and reduced cardiac NE spillover, benefits associated with increased cardiac sympathetic nerve sprouting [209]. Using a canine model of HF by combination of chronic MI and rapid ventricular pacing, Issa et al. [210] studied effects of TSCS on malignant ventricular arrhythmias evoked by a brief period of ischemia with results showing a significant reduction from $59 \%$ in control group to $23 \%$ by TSCT.

\section{Carotid body denervation (CBD)}

Carotid chemoreceptor mediates excitatory affluent input to the brainstem evoking over-activation of cardiovascular sympathetic drive. Studies have shown that carotid body chemoreceptors are activated in the setting of $\mathrm{HF}$ contributing significantly to autonomic dysfunction, disordered breathing and worsening of HF [211]. Preclinical studies have provided strong evidence for therapeutic potential of HF by CBD. In rat HF model due to chronic MI for 16 weeks, both carotid body chemoreflex activity and sympathetic outflow rate were enhanced [212]. And CBD performed either immediately or two-week post-MI reduced central sympathetic neuronal activation and sympathetic outflow, limited abnormal sleep pattern; when performed earlier, improved survival (85\% vs. 45\%) and cardiac function, and reduced frequency of ventricular arrhythmias [212]. Using Dahl salt-sensitive rats with hypertension and HF, Fujii et al. [213] observed that CBD sensitized pressure-natriuresis, blunted hyper tension, and improved cardiac function. Importantly, hypertension-associated myocardial remodeling, i.e. hypertrophy and fibrosis, was significantly attenuated. And these beneficial effects were associated with a $65 \%$ 
improvement in the survival at the end of 10-week study period. In addition, there was a sustained reduction in 24-h urine NE content, indicative of inhibited sympathetic tone, which might underlie the beneficial effects of CBD.

\section{Vagal nerve stimulation (VNS)}

Studies have documented beneficial effects of VNS on HF through several mechanisms including improvements of autonomic balance via sympathetic inhibition, inhibition of activity of the renin-angiotensin system, and antiinflammatory action [214]. In a rat model of HF due to MI, VNS was shown to limit the extent of ventricular remodeling, preserve LV contractile function, increase exercise capacity and improve survival, albeit infarct size was comparable between control and VNS groups [215, 216]. In a canine model of rapid-pacing induced HF, VNS significantly reduced LV dilatation and improved LVEF. VNS was also demonstrated to improve heart rate variability or baroreflex sensitivity, and reverse increment of circulating levels of NE, Ang-II and C-reactive protein [214].

\section{Renal sympathetic denervation (RSD)}

Initially being developed for treatment of resistant hypertension [207], a number of preclinical studies as well as several small-scale clinical trials have explored effects of RSD on HF. Using a porcine model of HF induced by combination of coronary artery occlusion and rapid pacing, Liao et al. [217] reported that bilateral RSD, using a clinically tested percutaneous device, is well tolerated and effective in achieving renal denervation with reduced blood NE gradient crossing kidneys or crossing the heart. A few studies have tested effect of RSD on HF induced by MI. In pigs subjected to IR (75 min ischemia), RSD was performed 6 weeks post-IR, and animals were followed for a further 12-week period [218]. RSD was effective in this model measured by reduction in renal NE content and lower circulating levels of angiotensin-II. Importantly, RSD significantly reduced LV end-diastolic volume and improved LVEF [218]. Cardioprotection by RSD was also reported in a canine HF model induced by intra-coronary injection with ethanol to induce embolization [219]. At four weeks after coronary embolism, dogs with RSD showed significantly attenuated LV dilatation and better preservation of LV function. Interestingly, expression in the myocardium and hypothalamus of several inflammatory factors, like IL-6, MCP-1 (monocyte chemoattractant protein-1), tumour necrosis factor- $\alpha$ (TNF $\alpha$ ) and NF-kB (nuclear factor $\kappa$-light chain-enhancer of activated B cells), was significantly lower in RSD relative to sham-procedure controlled HF animals, indicating attenuated cardiac and central inflammatory signaling by RSD [219]. Similar beneficial effects by RSD was also reported in a very recent canine study with HF induced by rapid ventricular pacing [220]. Success in RSD was confirmed by significant reduction in renal NE content, and beneficial effects of RSD was evidenced by ameliorated $\mathrm{LV}$ remodelling, better preservation of $\mathrm{LV}$ function and reduced myocardial fibrosis. Furthermore, HF animals displayed overactivity of central reninangiotensin-system, measured as higher levels of angII, AT1-receptor, angiotensin-converting enzyme, but reduction in both ACE2 and Ang1-7. These changes all reversed by RSD [220]. Zhang et al. [221] recently studied cardiac electrophysiology and onset of ventricular arrhythmias in dogs with chronic MI. In animals with RSD, frequency of ventricular arrhythmias attenuated spontaneous or stimulated ventricular arrhythmias, reduced dispersion and heterogeneity of effective refractory period relative to control group. Importantly, these changes were accompanied with significant reduction in circulating levels of catecholamines and lower peripheral sympathetic nervous discharges, evidence of attenuated efferent sympathetic tone by RSD [221]. Antiarrhythmic property of RSD was also reported in a rat model of chronic MI, efficacy associated with significant reduction in cardiac fibrosis [222]. In another study on SHRs and control rats subjected to IR (45 min ischemia) and studied up to 14 weeks, Polhemus et al. [223] tested therapeutic effects by administrating cardiosphere-derived stem cells at different time-points including early phase (i.e. $20 \mathrm{~min}$ following reperfusion), without or with RSD performed at 4 weeks post IR. RSD, but not stem-cell therapy, effectively reduced renal contents of NE and renal sympathetic outflow, as well as circulating levels of ang-II [223]. By comparing therapeutic efficacy of several interventions, Polhemus et al. [223] further showed that whereas stem-cell administration given alone in acute phase did not show benefits, combination of early cell administration and RSD limited the extent of LV remodelling, cardiac fibrosis and improved systolic function, efficacy akin to that by repeated stem-cell administration. While the exact mechanism for the synergistic efficacy remains unclear, this study provided promising evidence for a role of RSD in post-MI stem-cell therapy for ameliorating LV remodelling and dysfunction. 


\section{Clinical studies on device-based neuromodulation}

Thus, findings from preclinical studies on a variety of HF models have provided strong support for the beneficial outcomes by device-based neuronal interventions. There have been several clinical studies on therapeutic potential for HF by these device-based interventions. Gold et al. [224] reported that in a total of 707 patients with chronic HFrEF (EF < 40\%, NYHA-class III), VNS for a mean period of 16 months had no effect on LV remodelling, function or mortality, albeit there were improvements in quality of life. In DEFEAT-HF trial that included 66 patients with severe HF (NYHA-class III, average LVEF 27\%), TSCS delivered through implantable defibrillator for a 6-month period failed in providing beneficial clinical outcomes [225]. In patients with HF due to DCM or ischemic cardiomyopathy (LVEF $<40 \%$, NYHA-class II-III), Hopper et al. [226] treated patients with RSD or routine medication, followed them for a period 12 months, and observed significantly lower levels of NT-proBNP and improved glucose-tolerance test, without changes in LVEF, 6-min walking distance (6MWD), or estimated-glomerular filtration rate (eGFR). Nevertheless, a recent meta-analysis reviewed data from five clinical trials on patients with HFrEF (total 1,074 patients who received device-based therapies including TSCS, CBD, RSD or VNS). Based on five key clinical parameters (NYHA-class, 6MWD, BNP, MLHFQ-score and LV systolic volume), pooled data strongly indicate that neuromodulation therapy significantly improved functional status and quality of life in patients with HFrEF [227]. In a recent clinical study on eight patients with DCM and carrying implantable cardioverter defibrillator, and followed up for 15 months, RSD significantly reduced the frequency of ventricular arrhythmias (post-RSD 0.10 vs. pre-RSD 3.17 episodes/per month) [228].

\section{Future perspectives}

Our understanding on the sympatho-adrenergic mechanisms in HF has advanced significantly thanks to intense research conducted over the last seven decades. Ironically, however, two fundamental questions that were raised many years ago remain to be fully addressed: Whether alterations in sympathetic nerves (pre-synaptic) and $\beta A R$ (post-synaptic) in the failing heart detrimental or compensatory? What are the mechanisms by which $\beta$-blockers are effective in treatment of HF? As referred in this review, further research is warranted in several specific areas that hold promise of translational breakthrough.

\section{Less explored areas of cardiac $\beta A R$ actions}

Mitochondrial dysfunction and metabolic remodeling are regarded as the common mechanism leading to the development and worsening of HF. Whether sympatho$\beta A R$ signaling affects cardiac mitochondrial function remains much less investigated. With the recent demonstration of $\beta A R$ signaling via Hippo pathway [114], we are investigating myocardial mitochondrial function and metabolism. Using two cardiomyopathy mouse models

\section{Downregulation of mitochondrial gene-sets}

Hippo activation model
- Fatty acid $\beta$-oxidation
- Tri-citric acid cycle
- BCAA catabolism
- Respiratory electron transport
- ATP synthesis \& heat production
- Mitochondria protein import
- Mitochondria translation
- Mitochondria biogenesis
- Pyruvate metabolism

BAR activation model
- Mitochondrial respiratory chain
- Inner membrane complex
- Fatty acid metabolism
- Oxidoreductase complex
- Coenzyme \& cofactor binding
- NADH dehydrogenase complex
- Acyl-CoA dehydrogenases
- Mitochondria protein import

Upregulation of fibrotic gene-sets

\begin{tabular}{|l||l|}
\hline \multicolumn{1}{|c|}{ Hippo activation model } & \multicolumn{1}{c|}{ $\boldsymbol{\beta A R}$ activation model } \\
- Collagen formation & - Collagen binding \& trimerization \\
- Collagen biosynthesis \& modifying & - Collagen fibril organization \\
- Collagen chain trimerization & - Collagen fibre crosslinking \& assembly \\
- Collagen fibre crosslinking \& assembly & - Collagen-containing ECM \\
- Elastic fibre formation & - Fibronectin binding \\
- ECM proteoglycans & - ECM structure organization \\
- ECM organization & \\
\hline
\end{tabular}

Figure 9: Genetic activation of either $\beta A R$ or Hippo signaling pathway induces similar alterations in cardiotranscriptome by RNA sequencing. Data were from adult transgenic (TG) mouse models with cardiac overexpression of $\beta_{2} A R\left(\beta_{2}-\mathrm{TG}\right)$ or mammalian sterile-20-like kinase 1 (Mst1TG). In both models, RNA sequencing of the left ventricular myocardium revealed profound downregulation of numerous gene-sets of mitochondrial dynamics or metabolism, together with upregulation of fibrotic gene-sets. Data are based on published study [107] and our unpublished findings. BCAA: branched chain amino acids; ECM: extracellular matrix; NADH: nicotinamide adenine dinucleotide. 
due to transgenic activation of $\beta A R\left(\beta_{2}-\mathrm{TG}\right)$ or Mst1 (Mst1-TG) as upper-stream kinase of Hippo signaling, our studies thus far have demonstrated significant abnormalities in cardiotranscriptome with over $40 \%$ genes dysregulated in both models. Importantly, bioinformatic analyses of RNAseq data revealed that similar in both models, mitochondrion-related gene-sets are among those most significantly downregulated, and in contrary, pro-fibrotic gene-sets are among the most significantly upregulated gene-sets (Figure 9, and our unpublished finding) [107]. The similarity in both models of these changes in transcriptome strongly indicates a pivotal role of the $\beta$ AR-Hippo signaling pathway in mediating mitochondrial abnormalities seen in the failing heart. Other signaling mechanisms also likely contribute to metabolic abnormalities, including GRK2 mediated insulin-resistance [229], and enhanced ROS generation upon $\beta A R$ overactivation. Currently there has been lack of effective drugs that exert mitochondria protective action. Progress in this filed would widen our understanding on adverse $\beta$-adrenergic signaling in the heart and allow for development of novel therapeutic intervention targeting mitochondrial dysfunction and abnormal energy metabolism (Figure 9). Another intriguing area is proangiogenesis action mediated by $\beta_{2} \mathrm{AR}$, as reported by numerous studies on cancer tissues [230]. The similar angiogenesis due to $\beta_{2} \mathrm{AR}$ activation was also observed in the heart [231]. Considering the significance of angiogenesis in the heart, it is worthwhile to explore the potential role of such apparently compensatory action mediated by $\beta_{2} \mathrm{AR}$ in $\mathrm{HF}$.

\section{Unmet needs in drug development targeting $\beta$-adrenergic signaling}

There are apparent limitations of current $\beta$-blocking therapy, given that the sympatho- $\beta A R$ activation bears compensatory significance. Certain cohorts of HF patients show $\beta$-blocker intolerance for reasons including worsening HF symptoms, bradycardia, orthostatic hypotension, fatigue or disease-like asthma. In addition, clinical studies have revealed that in HF patients with atrial fibrillation, $\beta$-blocker therapy failed in achieving benefits assessed by reduction in risk of cardiovascular events like $\mathrm{HF}$ re-hospitalization and survival [232]. Anaemia is one of commonly comorbidities of $\mathrm{HF}$ and a recent J-CHF trail revealed that in patients with $\mathrm{HFrEF}$, the therapeutic effects of carvedilol, estimated by improvement of LVEF and normalization of elevated BNP, were blunted in patients complicated with anaemia [233]. Furthermore, $\beta$-blocking therapy may have limited effect in patients who are positive in $\beta_{1}$ AR-AAb $[116,118]$. Although reasons remain unclear for the blunted efficacy of $\beta$-blockers in these clinical scenarios, a very likely explanation is the non-selective blockade of $\beta A R$ signaling by current $\beta$-blockers. It would be desirable to develop drugs for specific inhibition of adverse signaling pathways sparing the compensatory signaling. This requires further in-depth understanding on $\beta$-adrenergic signaling networks, and identify key and drugable signal molecules. An alternative approach is the development of biased ligands. The biased ligand refers to a specific ligand that could stimulate a fraction of signal molecules of a given receptor thereby activating only desired downstream effects while avoiding potential adverse effects. This concept has stimulated research on development of biased ligands of GPCRs. Carvedilol is classically defined as a non-selective $\beta$-antagonist and widely used for HF therapy. This drug has been shown to act as a biased $\beta_{2} \mathrm{AR}$ ligand stimula ting $\beta$-arrestin-dependent, but not G-protein-dependent signaling, such as activation of ERK signaling [234]. A recent study showed that use of carvedilol with such selective signaling is useful for treatment of skeletal muscle wasting, which is commonly seen in patients with severe HF [235]. Cardioprotection via $\beta_{2} \mathrm{AR}-\beta$-arrestin biased signaling has also been achieved both in vitro and in vivo with the use of a small peptide (ICL1-9) [39, 236]. Development of ligands that selectively activate $\beta$-arrectin 2 and/or suppress $\beta$-arrestin1 also hold promise for future HF therapy by promoting cardiac beneficial while limiting detrimental signaling.

\section{$\beta A R$ signaling in hematopoietic/immune cells and fibroblasts}

Last two decades have witnessed major progress in our understanding regulation by SNS- $\beta$ AR of inflammatory cells (hematopoietic cells, immune cells) and fibroblasts, cell types critical in fibrogenesis. By regulating tissue damage as well as healing processes, inflammation plays a key role in heart disease and HF. However, clinical trials of drugs targeting inflammatory molecules for treatment of heart disease have yielded disappointing outcomes and new strategy is yet to be established. With increasing body of knowledge in this field, it is likely to establish new therapeutic strategy for HF by using selective $\beta A R$ agonists and antagonists to regulate inflammatory homeostasis. To achieve precise fineturning of immune responses without unwanted adverse effect, such pharmacological regulation of the $\beta A R$-immune axis would be aetiology-dependent, and key factors to be 
considered include the timing and duration of therapeutic targeting of $\beta A R s$ in immune cell. Furthermore, there is strong evidence for interactions, likely through the paracrine mechanism, between heterogeneous cells, i.e. cardiomyocytes, fibroblasts, endothelial cells or inflammatory cells, contributing to myocardial remodeling in HF. The role of $\beta A R$ in mediating communication between different cell types deserves further investigation.

\section{Role of sympatho-adrenergic mechanism in subtypes of $\mathrm{HF}$}

Current understanding on changes in the SNS in HF has largely come from research on patients with reduced LVEF (HFrEF). It has now been well recognized that approximately half of all patients with HF have preserved LVEF (HFpEF) vs. the rest exhibiting moderately-reduced or reduced LVEF (HFmrEF, HFrEF). However, studies on the SNS in HFpEF are sparse. It is critical to conduct comparative research to explore the sympathetic nervous activity on patients or animals with HFpEF vs. HFrEF, given that establishment of effective therapy for HFpEF would be difficult without better understanding of HFpEF pathophysiology, including the sympathy-adrenergic mechanism and the use of $\beta$-blocking therapy. In this regards, two very recent studies on patients with chronic $\mathrm{HF}$ have revealed that circulating NE level was higher in patients with HFrEF than those with HFpEF, and that patients with HFmrEF had NE level comparable to HFpEF subgroup [237, 238]. Interestingly, elevated NE level remains to be the independent predictor for long-term prognosis in all subtypes of HF patients albeit the predictive power is the strongest in HFrEF vs. other subtypes.

\section{Better understanding sympathetic nerve remodelling in $\mathrm{HF}$}

Driven by sustained afferent reflexes, cardiac sympathetic efferent activity is enhanced in the setting of HF. This, together with alterations in a group of neuroregulatory molecules like NGF and LIF, result in profound remodelling of sympathetic nerves and ganglion-localized sympathetic neurons. Whereas current information remains somewhat fragmented, the features of such remodelling likely depend on the stage and aetiology of HF, forming a vital part of HF pathophysiology. Progress in this area would be expected to shade light on neuronal mechanisms in development of $\mathrm{HF}$ and arrhythmogenesis.

\section{Neuromodulation for centrally mediated suppression of sympathetic activity}

The management of symptoms and the strategy for improving prognosis of HF patients have largely been based on pharmacological treatments. Modern cardiology leads the progress of device-based therapies for conditions that traditionally could only be treated with medications. To achieve autonomic neuromodulation for treatment of $\mathrm{HF}$, centrally acting agents (e.g. imidazole compounds) or device-based interventions hold promise to be further established as effective neuromodulatory therapies for $\mathrm{HF}$ (Figure 8). In-depth investigation, including clinical trial, is urgently needed on how device-based neuronal interventions, such as RSD, reduces the severity of HF and arrhythmic burden. It is anticipated that this filed would add new dimension to future HF therapy.

Research funding: The author's own research works referred in this review have been funded by competitive fellowship or project grants from the National Health and Medical Research Council of Australia (236884, 1032687, 1043026, 1081710), National Heart Foundation of Australia (G03M1126, G10M5126), and the National Science Foundation of China (81870223, 81870300).

Competing interests: The author has no conflict of interest to declare.

Ethical approval: There is no ethical issue involved in this work.

\section{References}

1. Armour JA, Murphy DA, Yuan BX, Macdonald S, Hopkins DA. Gross and microscopic anatomy of the human intrinsic cardiac nervous system. Anat Rec 1997;247:289-98.

2. Cohn JN, Levine TB, Olivari MT, Garberg V, Lura D, Francis GS, et al. Plasma norepinephrine as a guide to prognosis in patients with chronic congestive heart failure. N Engl J Med 1984;311:819-23.

3. Hartupee J, Mann DL. Neurohormonal activation in heart failure with reduced ejection fraction. Nat Rev Cardiol 2017;14:30-8.

4. Kaye DM, Lambert GW, Lefkovits J, Morris M, Jennings G, Esler MD. Neurochemical evidence of cardiac sympathetic activation and increased central nervous system norepinephrine turnover in severe congestive heart failure. J Am Coll Cardiol 1994;23:570-8.

5. Parati G, Esler M. The human sympathetic nervous system: its relevance in hypertension and heart failure. Eur Heart J 2012;33: 1058-66.

6. Grassi G, Quarti-Trevano F, Esler MD. Sympathetic activation in congestive heart failure: an updated overview. Heart Fail Rev 2021; 26:173-82.

7. Cohn JN. Abnormalities of peripheral sympathetic nervous system control in congestive heart failure. Circulation 1990;82:159-67. 
8. Esler M, Kaye D. Measurement of sympathetic nervous system activity in heart failure: the role of norepinephrine kinetics. Heart Fail Rev 2000;5:17-25.

9. Brunner-La Rocca HP, Esler MD, Jennings GL, Kaye DM. Effect of cardiac sympathetic nervous activity on mode of death in congestive heart failure. Eur Heart J 2001;22:1136-43.

10. Kaye DM, Lefkovits J, Jennings GL, Bergin P, Broughton A, Esler MD. Adverse consequences of high sympathetic nervous activity in the failing human heart. J Am Coll Cardiol 1995;26:1257-63.

11. Seravalle G, Quarti-Trevano F, Dell'Oro R, Gronda E, Spaziani D, Facchetti R, et al. Sympathetic and baroreflex alterations in congestive heart failure with preserved, midrange and reduced ejection fraction. J Hypertens 2019;37:443-8.

12. Kingwell BA, Thompson JM, Kaye DM, McPherson GA, Jennings GL, Esler MD. Heart rate spectral analysis, cardiac norepinephrine spillover, and muscle sympathetic nerve activity during human sympathetic nervous activation and failure. Circulation 1994;90:234-40.

13. Zelt JGE, deKemp RA, Rotstein BH, Nair GM, Narula J, Ahmadi A, et al. Nuclear imaging of the cardiac sympathetic nervous system: a disease-specific interpretation in heart failure. JACC Cardiovasc Imag 2020;13:1036-54.

14. Matsuo S, Nakajima K, Nakata T. Prognostic value of cardiac sympathetic nerve imaging using long-term follow-up dataischemic vs. non-ischemic heart failure etiology. Circ J 2016;80: 435-41.

15. Du XJ, Cox HS, Dart AM, Esler MD. Sympathetic activation triggers ventricular arrhythmias in rat heart with chronic infarction and failure. Cardiovasc Res 1999;43:919-29.

16. Nguyen MN, Kiriazis H, Gao XM and Du XJ. Cardiac fibrosis and arrhythmogenesis. Compr Physiol 2017;7:1009-49.

17. Denniss AL, Dashwood AM, Molenaar P and Beard NA. Sarcoplasmic reticulum calcium mishandling: central tenet in heart failure? Biophys Rev 2020;12:865-78.

18. Desantiago J, Ai X, Islam M, Acuna G, Ziolo MT, Bers DM, et al. Arrhythmogenic effects of $\beta 2$-adrenergic stimulation in the failing heart are attributable to enhanced sarcoplasmic reticulum Ca load. Circ Res 2008;102:1389-97.

19. Shugg T, Hudmon A, Overholser BR. Neurohormonal regulation of IKs in heart failure: implications for ventricular arrhythmogenesis and sudden cardiac death. J Am Heart Assoc 2020;9:e016900.

20. Niaz T, Bos JM, Sorensen KB, Moir C, Ackerman MJ. Left cardiac sympathetic denervation monotherapy in patients with congenital long QT syndrome. Circ Arrhythm Electrophysiol 2020;13:e008830.

21. Schwartz PJ. Cardiac sympathetic denervation to prevent lifethreatening arrhythmias. Nat Rev Cardiol 2014;11:346-53.

22. Vaseghi M, Barwad P, Malavassi Corrales FJ, Tandri H, Mathuria $\mathrm{N}$, Shah R, et al. Cardiac sympathetic denervation for refractory ventricular arrhythmias. J Am Coll Cardiol 2017;69:3070-80.

23. Xiong L, Liu Y, Zhou M, Wang G, Quan D, Shen C, et al. Targeted ablation of cardiac sympathetic neurons improves ventricular electrical remodelling in a canine model of chronic myocardial infarction. Europace 2018;20:2036-44.

24. Chen PS, Chen LS, Fishbein MC, Lin SF, Nattel S. Role of the autonomic nervous system in atrial fibrillation: pathophysiology and therapy. Circ Res 2014;114:1500-15.

25. Ogawa M, Zhou S, Tan AY, Song J, Gholmieh G, Fishbein MC, et al. Left stellate ganglion and vagal nerve activity and cardiac arrhythmias in ambulatory dogs with pacing-induced congestive heart failure. J Am Coll Cardiol 2007;50:335-43.
26. Du XJ, Esler MD, Dart AM. Sympatholytic action of intravenous amiodarone in the rat heart. Circulation 1995;91:462-70.

27. Kaye DM, Dart AM, Jennings GL, Esler MD. Antiadrenergic effect of chronic amiodarone therapy in human heart failure. J Am Coll Cardiol 1999;33:1553-9.

28. Tachikawa H, Kodama M, Watanabe K, Takahashi T, Ma M, Kashimura T, et al. Amiodarone improves cardiac sympathetic nerve function to hold norepinephrine in the heart, prevents left ventricular remodeling, and improves cardiac function in rat dilated cardiomyopathy. Circulation 2005;111:894-9.

29. Lymperopoulos A, Rengo G, Koch WJ. Adrenergic nervous system in heart failure: pathophysiology and therapy. Circ Res 2013;113: 739-53.

30. Xiao H, Li H, Wang JJ, Zhang JS, Shen J, An XB, et al. IL-18 cleavage triggers cardiac inflammation and fibrosis upon beta-adrenergic insult. Eur Heart J 2018;39:60-9.

31. Zhao WB, Lu Q, Nguyen MN, Su Y, Ziemann M, Wang LN, et al. Stimulation of beta-adrenoceptors up-regulates cardiac expression of galectin-3 and BIM through the Hippo signalling pathway. Br J Pharmacol 2019;176:2465-81.

32. Du XJ, Gao XM, Wang B, Jennings GL, Woodcock EA, Dart AM. Agedependent cardiomyopathy and heart failure phenotype in mice overexpressing $\beta 2$-adrenergic receptors in the heart. Cardiovasc Res 2000;48:448-54.

33. Engelhardt S, Hein L, Wiesmann F, Lohse MJ. Progressive hypertrophy and heart failure in $\beta 1$-adrenergic receptor transgenic mice. Proc Natl Acad Sci U S A 1999;96:7059-64.

34. Liggett SB, Tepe NM, Lorenz JN, Canning AM, Jantz TD, Mitarai S, et al. Early and delayed consequences of $\beta 2$-adrenergic receptor overexpression in mouse hearts: critical role for expression level. Circulation 2000;101:1707-14.

35. Cleland JGF, Bunting KV, Flather MD, Altman DG, Holmes J, Coats AJS, et al. $\beta$-blockers for heart failure with reduced, mid-range, and preserved ejection fraction: an individual patient-level analysis of double-blind randomized trials. Eur Heart J 2018;39: 26-35.

36. Lechat P, Packer M, Chalon S, Cucherat M, Arab T, Boissel JP. Clinical effects of $\beta$-adrenergic blockade in chronic heart failure: a meta-analysis of double-blind, placebo-controlled, randomized trials. Circulation 1998;98:1184-91.

37. Peter PS, Brady JE, Yan L, Chen W, Engelhardt S, Wang Y, et al. Inhibition of $\mathrm{p} 38 \alpha$ MAPK rescues cardiomyopathy induced by overexpressed $\beta 2$-adrenergic receptor, but not beta 1-adrenergic receptor. J Clin Invest 2007;117:1335-43.

38. Grisanti LA, Schumacher SM, Tilley DG, Koch WJ. Designer approaches for $\mathrm{G}$ protein-coupled receptor modulation for cardiovascular disease. JACC Basic Transl Sci 2018;3: 550-62.

39. Grisanti LA, Thomas TP, Carter RL, de Lucia C, Gao E, Koch WJ, et al. Pepducin-mediated cardioprotection via $\beta$-arrestin-biased $\beta 2$-adrenergic receptor-specific signaling. Theranostics 2018;8: 4664-78.

40. Bristow MR, Hershberger RE, Port JD, Gilbert EM, Sandoval A, Rasmussen $R$, et al. $\beta$-Adrenergic pathways in nonfailing and failing human ventricular myocardium. Circulation 1990;82: 112-25.

41. Brodde OE. $\beta 1$ - and $\beta 2$-adrenoceptors in the human heart: properties, function, and alterations in chronic heart failure. Pharmacol Rev 1991;43:203-42.

42. Eisenhofer G, Friberg P, Rundqvist B, Quyyumi AA, Lambert G, Kaye DM, et al. Cardiac sympathetic nerve function in congestive heart failure. Circulation 1996;93:1667-76. 
43. Delehanty JM, Himura Y, Elam H, Hood WB, Jr, Liang CS. $\beta$-adrenoceptor downregulation in pacing-induced heart failure is associated with increased interstitial NE content. Am J Physiol Heart Circ Physiol 1994;266:H930-5.

44. Bristow MR. Mechanism of action of $\beta$-blocking agents in heart failure. Am J Cardiol 1997;80:26L-40.

45. Elnatan J, Molenaar P, Rosenfeldt FL, Summers RJ. Autoradiographic localization and quantitation of $\beta 1$ - and $\beta 2$-adrenoceptors in the human atrioventricular conducting system: a comparison of patients with idiopathic dilated cardiomyopathy and ischemic heart disease. J Mol Cell Cardiol 1994;26:313-23.

46. Bohm M, Flesch M, Schnabel P. Role of G-proteins in altered $\beta$-adrenergic responsiveness in the failing and hypertrophied myocardium. Basic Res Cardiol 1996;91(2 Suppl):47-51.

47. Daaka Y, Luttrell LM, Lefkowitz RJ. Switching of the coupling of the $\beta 2$-adrenergic receptor to different $\mathrm{G}$ proteins by protein kinase A. Nature 1997;390:88-91.

48. Black JW, Stephenson JS. Pharmacology of a new adrenergic $\beta$-receptor-blocking compound (Nethalide). Lancet 1962;2:311-4.

49. Waagstein F, Hjalmarson A, Varnauskas E, Wallentin I. Effect of chronic $\beta$-adrenergic receptor blockade in congestive cardiomyopathy. Br Heart J 1975;37:1022-36.

50. Waagstein F, Rutherford JD. The evolution of the use of $\beta$-blockers to treat heart failure: a conversation with Finn Waagstein, MD. Circulation 2017;136:889-93.

51. Waagstein F, Bristow MR, Swedberg K, Camerini F, Fowler MB, Silver MA, et al. Beneficial effects of metoprolol in idiopathic dilated cardiomyopathy. Metoprolol in dilated cardiomyopathy (MDC) trial study group. Lancet 1993;342:1441-6.

52. Waagstein F, Caidahl K, Wallentin I, Bergh CH, Hjalmarson A. Long-term $\beta$-blockade in dilated cardiomyopathy. Effects of short- and long-term metoprolol treatment followed by withdrawal and readministration of metoprolol. Circulation 1989; 80:551-63.

53. Xiao RP, Zhang SJ, Chakir K, Avdonin P, Zhu W, Bond RA, et al. Enhanced $G(i)$ signaling selectively negates $\beta 2$-adrenergic receptor (AR)-but not $\beta 1$-AR-mediated positive inotropic effect in myocytes from failing rat hearts. Circulation 2003;108:1633-9.

54. Zhu W, Petrashevskaya N, Ren S, Zhao A, Chakir K, Gao E, et al. Gibiased $\beta 2 A R$ signaling links GRK2 upregulation to heart failure. Circ Res 2012;110:265-74.

55. Nikolaev VO, Moshkov A, Lyon AR, Miragoli M, Novak P, Paur H, et al. $\beta 2$-adrenergic receptor redistribution in heart failure changes cAMP compartmentation. Science 2010;327:1653-7.

56. Schobesberger S, Wright P, Tokar S, Bhargava A, Mansfield C, Glukhov AV, et al. T-tubule remodelling disturbs localized $\beta 2$-adrenergic signalling in rat ventricular myocytes during the progression of heart failure. Cardiovasc Res 2017;113:770-82.

57. Gorelik J, Wright PT, Lyon AR, Harding SE. Spatial control of the $\beta A R$ system in heart failure: the transverse tubule and beyond. Cardiovasc Res 2013;98:216-24.

58. Manfra O, Frisk M, Louch WE. Regulation of cardiomyocyte T-tubular structure: opportunities for therapy. Curr Heart Fail Rep 2017;14:167-78.

59. Wright PT, Nikolaev VO, O'Hara T, Diakonov I, Bhargava A, Tokar $S$, et al. Caveolin-3 regulates compartmentation of cardiomyocyte $\beta 2$-adrenergic receptor-mediated cAMP signaling. J Mol Cell Cardiol 2014;67:38-48.
60. Kaumann A, Bartel S, Molenaar P, Sanders L, Burrell K, Vetter D, et al. Activation of $\beta 2$-adrenergic receptors hastens relaxation and mediates phosphorylation of phospholamban, troponin I, and C-protein in ventricular myocardium from patients with terminal heart failure. Circulation 1999;99:65-72.

61. Lang D, Holzem K, Kang C, Xiao M, Hwang HJ, Ewald GA, et al. Arrhythmogenic remodeling of $\beta 2$ versus $\beta 1$ adrenergic signaling in the human failing heart. Circ Arrhythm Electrophysiol 2015;8: 409-19.

62. Du XJ. Sympathoadrenergic mechanisms in functional regulation and development of cardiac hypertrophy and failure: findings from genetically engineered mice. Cardiovasc Res 2001;50: 443-53.

63. Lee GJ, Yan L, Vatner DE, Vatner SF. Mst1 inhibition rescues $\beta 1$-adrenergic cardiomyopathy by reducing myocyte necrosis and non-myocyte apoptosis rather than myocyte apoptosis. Basic Res Cardiol 2015;110:7.

64. Nguyen MN, Kiriazis H, Ruggiero D, Gao XM, Su Y, Jian A, et al. Spontaneous ventricular tachyarrhythmias in $\beta 2$-adrenoceptor transgenic mice in relation to cardiac interstitial fibrosis. Am J Physiol Heart Circ Physiol 2015;309:H946-57.

65. Nguyen MN, Su Y, Vizi D, Fang L, Ellims AH, Zhao WB, et al. Mechanisms responsible for increased circulating levels of galectin-3 in cardiomyopathy and heart failure. Sci Rep 2018;8: 8213.

66. Xu Q, Dalic A, Fang L, Kiriazis H, Ritchie RH, Sim K, et al. Myocardial oxidative stress contributes to transgenic $\beta 2$-adrenoceptor activation-induced cardiomyopathy and heart failure. Br J Pharmacol 2011;162:1012-28.

67. Du XJ, Autelitano DJ, Dilley RJ, Wang B, Dart AM, Woodcock EA. $\beta 2$-Adrenergic receptor overexpression exacerbates development of heart failure after aortic stenosis. Circulation 2000;101:71-7.

68. Sheridan DJ, Autelitano DJ, Wang B, Percy E, Woodcock EA, Du XJ. $\beta 2$-Adrenergic receptor overexpression driven by alpha-MHC promoter is downregulated in hypertrophied and failing myocardium. Cardiovasc Res 2000;47:133-41.

69. Du XJ, Gao XM, Jennings GL, Dart AM, Woodcock EA. Preserved ventricular contractility in infarcted mouse heart overexpressing B2-adrenergic receptors. Am J Physiol Heart Circ Physiol 2000; 279:H2456-63.

70. Wittstein IS, Thiemann DR, Lima JA, Baughman KL, Schulman SP, Gerstenblith G, et al. Neurohumoral features of myocardial stunning due to sudden emotional stress. N Engl J Med 2005;352: 539-48.

71. Paur H, Wright PT, Sikkel MB, Tranter MH, Mansfield C, O'Gara P, et al. High levels of circulating epinephrine trigger apical cardiodepression in a $\beta 2$-adrenergic receptor/Gi-dependent manner: a new model of Takotsubo cardiomyopathy. Circulation 2012;126:697-706.

72. Bouvet M, Blondeau JP, Lezoualc'h F. The Epac1 protein: pharmacological modulators, cardiac signalosome and pathophysiology. Cells 2019;8:1543.

73. Fazal L, Laudette M, Paula-Gomes S, Pons S, Conte C, Tortosa F, et al. Multifunctional mitochondrial Epac1 controls myocardial cell death. Circ Res 2017;120:645-57.

74. Szanda G, Wisniewski E, Rajki A, Spat A. Mitochondrial cAMP exerts positive feedback on mitochondrial $\mathrm{Ca}(2+)$ uptake via the recruitment of Epac1. J Cell Sci 2018;131:jcs215178. 
75. Giorgi C, Marchi S, Pinton P. The machineries, regulation and cellular functions of mitochondrial calcium. Nat Rev Mol Cell Biol 2018;19:713-30.

76. Metrich M, Lucas A, Gastineau M, Samuel JL, Heymes C, Morel E, et al. Epac mediates $\beta$-adrenergic receptor-induced cardiomyocyte hypertrophy. Circ Res 2008;102:959-65.

77. Laudette M, Coluccia A, Sainte-Marie Y, Solari A, Fazal L, Sicard P, et al. Identification of a pharmacological inhibitor of Epac1 that protects the heart against acute and chronic models of cardiac stress. Cardiovasc Res 2019;115:1766-77.

78. Lezoualc'h F, Fazal L, Laudette M, Conte C. Cyclic AMP sensor EPAC proteins and their role in cardiovascular function and disease. Circ Res 2016;118:881-97.

79. Laurent AC, Bisserier M, Lucas A, Tortosa F, Roumieux M, De Regibus A, et al. Exchange protein directly activated by CAMP 1 promotes autophagy during cardiomyocyte hypertrophy. Cardiovasc Res 2015;105:55-64.

80. Okumura S, Fujita T, Cai W, Jin M, Namekata I, Mototani Y, et al. Epac1-dependent phospholamban phosphorylation mediates the cardiac response to stresses. J Clin Invest 2014;124: 2785-801.

81. Pereira L, Cheng H, Lao DH, Na L, van Oort RJ, Brown JH, et al. Epac2 mediates cardiac $\beta 1$-adrenergic-dependent sarcoplasmic reticulum Ca2+ leak and arrhythmia. Circulation 2013;127:913-22.

82. Sato PY, Chuprun JK, Schwartz M, Koch WJ. The evolving impact of g protein-coupled receptor kinases in cardiac health and disease. Physiol Rev 2015;95:377-404.

83. Pfleger J, Gresham K, Koch WJ. G protein-coupled receptor kinases as therapeutic targets in the heart. Nat Rev Cardiol 2019; 16:612-22.

84. Sato PY, Chuprun JK, Ibetti J, Cannavo A, Drosatos K, Elrod JW, et al. GRK2 compromises cardiomyocyte mitochondrial function by diminishing fatty acid-mediated oxygen consumption and increasing superoxide levels. J Mol Cell Cardiol 2015;89:360-4

85. Woodall BP, Gresham KS, Woodall MA, Valenti MC, Cannavo A, Pfleger J, et al. Alteration of myocardial GRK2 produces a global metabolic phenotype. JCI Insight 2019;5:e123848.

86. Santulli G, Campanile A, Spinelli L, Assante di Panzillo E, Ciccarelli M, Trimarco B, et al. G protein-coupled receptor kinase 2 in patients with acute myocardial infarction. Am J Cardiol 2011; 107:1125-30.

87. Ciccarelli M, Sorriento D, Fiordelisi A, Gambardella J, Franco A, Del Giudice $C$, et al. Pharmacological inhibition of GRK2 improves cardiac metabolism and function in experimental heart failure. ESC Heart Fail 2020;7:1571-84.

88. Lymperopoulos A, Rengo G, Funakoshi H, Eckhart AD, Koch WJ. Adrenal GRK2 upregulation mediates sympathetic overdrive in heart failure. Nat Med 2007;13:315-23.

89. Bathgate-Siryk A, Dabul S, Pandya K, Walklett K, Rengo G, Cannavo $A$, et al. Negative impact of $\beta$-arrestin- 1 on postmyocardial infarction heart failure via cardiac and adrenaldependent neurohormonal mechanisms. Hypertension 2014;63: 404-12.

90. Mangmool S, Parichatikanond W, Kurose H. Therapeutic targets for treatment of heart failure: focus on GRKs and $\beta$-arrestins affecting $\beta A R$ signaling. Front Pharmacol 2018;9:1336.

91. McCrink KA, Maning J, Vu A, Jafferjee M, Marrero C, Brill A, et al. $\beta$-Arrestin2 improves post-myocardial infarction heart failure via Sarco(endo)plasmic reticulum $\mathrm{Ca}(2+)$-ATPase-dependent positive inotropy in cardiomyocytes. Hypertension 2017;70: 972-81.

92. McCrink KA, Maning J, Vu A, Jafferjee M, Marrero C, Brill A, et al. Cardiac $\beta$-arrestin2 improves contractility and adverse remodeling in heart failure, but is underexpressed in humans. J Am Coll Cardiol 2017;70:2948-9.

93. Noma T, Lemaire A, Naga Prasad SV, Barki-Harrington L, Tilley DG, Chen J, et al. $\beta$-Arrestin-mediated $\beta 1$-adrenergic receptor transactivation of the EGFR confers cardioprotection. J Clin Invest 2007;117:2445-58.

94. Watari K, Nakaya M, Nishida M, Kim KM, Kurose H. $\beta$-arrestin2 in infiltrated macrophages inhibits excessive inflammation after myocardial infarction. PLoS One 2013;8:e68351.

95. Belevych AE, Juranek I, Harvey RD. Protein kinase $C$ regulates functional coupling of $\beta 1$-adrenergic receptors to $\mathrm{Gi} / \mathrm{o}$ mediated responses in cardiac myocytes. FASEB J 2004;18: 367-9.

96. Martin NP, Whalen EJ, Zamah MA, Pierce KL, Lefkowitz RJ. PKA-mediated phosphorylation of the $\beta 1$-adrenergic receptor promotes Gs/Gi switching. Cell Signal 2004;16: 1397-403.

97. Keller K, Maass M, Dizayee S, Leiss V, Annala S, Koth J, et al. Lack of Gai2 leads to dilative cardiomyopathy and increased mortality in $\beta 1$-adrenoceptor overexpressing mice. Cardiovasc Res 2015;108:348-56.

98. Molenaar P, Christ T, Ravens U, Kaumann A. Carvedilol blocks $\beta 2$ - more than $\beta 1$-adrenoceptors in human heart. Cardiovasc Res 2006;69:128-39.

99. Wang J, Hanada K, Staus DP, Makara MA, Dahal GR, Chen Q, et al. Galphai is required for carvedilol-induced beta1 adrenergic receptor $\beta$-arrestin biased signaling. Nat Commun 2017;8:1706

100. Wang Q, Wang Y, West TM, Liu Y, Reddy GR, Barbagallo F, et al. Carvedilol induces biased $\beta 1$ adrenergic receptor-nitric oxide synthase 3-cyclic guanylyl monophosphate signaling to promote cardiac contractility. Cardiovasc Res 2021;117: 2237-51.

101. Yu F-X, Zhao B, Guan K-L. Hippo pathway in organ size control, tissue homeostasis, and cancer. Cell 2015;163:811-28.

102. Leach JP, Heallen T, Zhang M, Rahmani M, Morikawa Y, Hill MC, et al. Hippo pathway deficiency reverses systolic heart failure after infarction. Nature 2017;550:260-4.

103. Wang J, Liu S, Heallen T, Martin JF. The Hippo pathway in the heart: pivotal roles in development, disease, and regeneration. Nat Rev Cardiol 2018;15:672-84.

104. Xin M, Kim Y, Sutherland LB, Murakami M, Qi X, McAnally J, et al. Hippo pathway effector Yap promotes cardiac regeneration. Proc Natl Acad Sci U S A 2013;110:13839-44.

105. Del Re DP, Yang Y, Nakano N, Cho J, Zhai P, Yamamoto T, et al. Yes-associated protein isoform 1 (Yap1) promotes cardiomyocyte survival and growth to protect against myocardial ischemic injury. J Biol Chem 2013;288:3977-88.

106. Liu R, Lee J, Kim BS, Wang Q, Buxton SK, Balasubramanyam N, et al. Tead1 is required for maintaining adult cardiomyocyte function, and its loss results in lethal dilated cardiomyopathy. JCI Insight 2017;2:e93343.

107. Nguyen MN, Ziemann M, Kiriazis H, Su Y, Thomas Z, Lu Q, et al. Galectin-3 deficiency ameliorates fibrosis and remodeling in dilated cardiomyopathy mice with enhanced Mst1 signaling. Am J Physiol Heart Circ Physiol 2019;316:H45-60. 
108. Yamamoto S, Yang G, Zablocki D, Liu J, Hong C, Kim SJ, et al. Activation of Mst1 causes dilated cardiomyopathy by stimulating apoptosis without compensatory ventricular myocyte hypertrophy. J Clin Invest 2003;111:1463-74.

109. Chen SN, Gurha P, Lombardi R, Ruggiero A, Willerson JT, Marian AJ. The hippo pathway is activated and is a causal mechanism for adipogenesis in arrhythmogenic cardiomyopathy. Circ Res 2014;114:454-68.

110. Vita GL, Polito F, Oteri R, Arrigo R, Ciranni AM, Musumeci O, et al. Hippo signaling pathway is altered in Duchenne muscular dystrophy. PLoS One 2018;13:e0205514.

111. Yu FX, Zhao B, Panupinthu N, Jewell JL, Lian I, Wang LH, et al. Regulation of the Hippo-YAP pathway by G-protein-coupled receptor signaling. Cell 2012;150:780-91.

112. Kim M, Kim M, Lee S, Kuninaka S, Saya H, Lee H, et al. cAMP/PKA signalling reinforces the LATS-YAP pathway to fully suppress YAP in response to actin cytoskeletal changes. EMBO I 2013;32: 1543-55.

113. Dethlefsen C, Hansen LS, Lillelund C, Andersen C, Gehl J, Christensen JF, et al. Exercise-induced catecholamines activate the hippo tumor suppressor pathway to reduce risks of breast cancer development. Cancer Res 2017;77:4894-904.

114. Du XJ, Zhao WB, Nguyen MN, Lu Q, Kiriazis H. $\beta$-Adrenoceptor activation affects galectin-3 as a biomarker and therapeutic target in heart disease. Br J Pharmacol 2019;176:2449-64.

115. Lee YY, Moujalled D, Doerflinger M, Gangoda L, Weston R, Rahimi A, et al. CREB-binding protein (CBP) regulates $\beta$-adrenoceptor ( $\beta$-AR)-mediated apoptosis. Cell Death Differ 2013;20:941-52.

116. Dungen HD, Dordevic A, Felix SB, Pieske B, Voors AA, McMurray JJV, et al. $\beta 1$-Adrenoreceptor autoantibodies in heart failure: physiology and therapeutic implications. Circ Heart Fail 2020; 13:e006155.

117. Jahns R, Boivin V, Siegmund C, Inselmann G, Lohse MJ, Boege F. Autoantibodies activating human $\beta 1$-adrenergic receptors are associated with reduced cardiac function in chronic heart failure. Circulation 1999;99:649-54.

118. Patel PA, Hernandez AF. Targeting anti- $\beta 1$-adrenergic receptor antibodies for dilated cardiomyopathy. Eur J Heart Fail 2013;15: 724-9.

119. Wallukat G, Morwinski M, Kowal K, Forster A, Boewer V, Wollenberger A. Autoantibodies against the $\beta$-adrenergic receptor in human myocarditis and dilated cardiomyopathy: $\beta$-adrenergic agonism without desensitization. Eur Heart J 1991; 12:178-81.

120. Lv T, Du Y, Cao N, Zhang S, Gong Y, Bai Y, et al. Proliferation in cardiac fibroblasts induced by $\beta 1$-adrenoceptor autoantibody and the underlying mechanisms. Sci Rep 2016;6:32430.

121. Jahns R, Boivin V, Krapf T, Wallukat G, Boege F, Lohse MJ. Modulation of $\beta 1$-adrenoreceptor activity by domain-specific antibodies and heart failure-associated autoantibodies. J Am Coll Cardiol 2000;36:1280-7.

122. Pei J, Li N, Chen J, Li X, Zhang Y, Wang Z, et al. The predictive values of $\beta 1$-adrenergic and $M 2$ muscarinic receptor autoantibodies for sudden cardiac death in patients with chronic heart failure. Eur J Heart Fail 2012;14:887-94.

123. Du Y, Yan L, Du H, Wang L, Ding F, Quan L, et al. $\beta 1$-Adrenergic receptor autoantibodies from heart failure patients enhanced TNF- $\alpha$ secretion in RAW264.7 macrophages in a largely PKA-dependent fashion. J Cell Biochem 2012;113:3218-28.
124. Cao N, Chen H, Bai Y, Yang X, Xu W, Hao W, et al. $\beta 2$-adrenergic receptor autoantibodies alleviated myocardial damage induced by $\beta 1$-adrenergic receptor autoantibodies in heart failure. Cardiovasc Res 2018;114:1487-98.

125. Mendez-Ferrer S, Battista M, Frenette PS. Cooperation of $\beta 2$ and $\beta 3$-adrenergic receptors in hematopoietic progenitor cell mobilization. Ann N Y Acad Sci 2010;1192:139-44.

126. Grisanti LA, Gumpert AM, Traynham CJ, Gorsky JE, Repas AA, Gao $E$, et al. Leukocyte-expressed $\beta 2$-adrenergic receptors are essential for survival after acute myocardial injury. Circulation 2016;134:153-67.

127. Grisanti LA, Traynham CJ, Repas AA, Gao E, Koch WJ, Tilley DG. $\beta 2$-Adrenergic receptor-dependent chemokine receptor 2 expression regulates leukocyte recruitment to the heart following acute injury. Proc Natl Acad Sci U S A 2016;113: 15126-31.

128. Heidt T, Sager HB, Courties G, Dutta P, Iwamoto Y, Zaltsman A, et al. Chronic variable stress activates hematopoietic stem cells. Nat Med 2014;20:754-8.

129. Courties G, Herisson F, Sager HB, Heidt T, Ye Y, Wei Y, et al. Ischemic stroke activates hematopoietic bone marrow stem cells. Circ Res 2015;116:407-17.

130. Swirski FK, Nahrendorf M, Etzrodt M, Wildgruber M, CortezRetamozo V, Panizzi P, et al. Identification of splenic reservoir monocytes and their deployment to inflammatory sites. Science 2009;325:612-6.

131. Sager HB, Hulsmans M, Lavine KJ, Moreira MB, Heidt T, Courties $\mathrm{G}$, et al. Proliferation and recruitment contribute to myocardial macrophage expansion in chronic heart failure. Circ Res 2016; 119:853-64.

132. Lamkin DM, Ho HY, Ong TH, Kawanishi CK, Stoffers VL, Ahlawat $\mathrm{N}$, et al. $\beta$-Adrenergic-stimulated macrophages: comprehensive localization in the M1-M2 spectrum. Brain Behav Immun 2016;57:338-46.

133. Lorton D, Bellinger DL. Molecular mechanisms underlying $\beta$-adrenergic receptor-mediated cross-talk between sympathetic neurons and immune cells. Int J Mol Sci 2015;16: 5635-65.

134. Fujiu K, Shibata M, Nakayama Y, Ogata F, Matsumoto S, Noshita K, et al. A heart-brain-kidney network controls adaptation to cardiac stress through tissue macrophage activation. Nat Med 2017;23:611-22.

135. Gao XM, Moore XL, Liu Y, Wang XY, Han LP, Su Y, et al. Splenic release of platelets contributes to increased circulating platelet size and inflammation after myocardial infarction. Clin Sci (Lond) 2016;130:1089-104.

136. Wang XY, Yu HY, Zhang YY, Wang YP, Feng XH, Li ZP, et al. Serial changes of mean platelet volume in relation to Killip Class in patients with acute myocardial infarction and primary percutaneous coronary intervention. Thromb Res 2015;135: 652-8.

137. Grisan F, Burdyga A, lannucci LF, Surdo NC, Pozzan T, Di Benedetto $G$, et al. Studying $\beta 1$ and $\beta 2$ adrenergic receptor signals in cardiac cells using FRET-based sensors. Prog Biophys Mol Biol 2020;154:30-8.

138. Delaunay M, Osman H, Kaiser S, Diviani D. The role of cyclic AMP signaling in cardiac fibrosis. Cells 2019;9:69.

139. Chen C, Du J, Feng W, Song Y, Lu Z, Xu M, et al. $\beta$-Adrenergic receptors stimulate interleukin- 6 production through Epacdependent activation of $\mathrm{PKC} \delta / \mathrm{p} 38$ MAPK signalling in 
neonatal mouse cardiac fibroblasts. Br J Pharmacol 2012;166: 676-88.

140. Turner NA, Porter KE, Smith WH, White HL, Ball SG, Balmforth AJ. Chronic $\beta 2$-adrenergic receptor stimulation increases proliferation of human cardiac fibroblasts via an autocrine mechanism. Cardiovasc Res 2003;57:784-92.

141. Yin F, Li P, Zheng M, Chen L, Xu Q, Chen K, et al. Interleukin-6 family of cytokines mediates isoproterenol-induced delayed STAT3 activation in mouse heart. J Biol Chem 2003;278: 21070-5.

142. Zhang Y, Hou MC, Li JJ, Qi Y, Zhang Y, She G, et al. Cardiac $\beta$-adrenergic receptor activation mediates distinct and cell typedependent changes in the expression and distribution of connexin 43. J Cell Mol Med 2020;24:8505-17.

143. Li J, Philip JL, Xu X, Theccanat T, Abdur Razzaque M, Akhter SA. $\beta$-Arrestins regulate human cardiac fibroblast transformation and collagen synthesis in adverse ventricular remodeling. J Mol Cell Cardiol 2014;76:73-83.

144. Travers JG, Kamal FA, Valiente-Alandi I, Nieman ML, Sargent MA, Lorenz JN, et al. Pharmacological and activated fibroblast targeting of G $\beta \gamma$-GRK2 after myocardial ischemia attenuates heart failure progression. J Am Coll Cardiol 2017; 70:958-71.

145. Tanner MA, Thomas TP, Maitz CA, Grisanti LA. $\beta 2$-Adrenergic receptors increase cardiac fibroblast proliferation through the Galphas/ERK1/2-dependent secretion of interleukin-6. Int J Mol Sci 2020;21:8507.

146. Yin F, Wang YY, Du JH, Li C, Lu ZZ, Han C, et al. Noncanonical cAMP pathway and $\mathrm{p} 38$ MAPK mediate $\beta 2$-adrenergic receptorinduced IL-6 production in neonatal mouse cardiac fibroblasts. I Mol Cell Cardiol 2006;40:384-93.

147. Bageghni SA, Hemmings KE, Zava N, Denton CP, Porter KE, Ainscough JFX, et al. Cardiac fibroblast-specific p38 $\alpha$ MAP kinase promotes cardiac hypertrophy via a putative paracrine interleukin-6 signaling mechanism. FASEB J 2018;32:4941-54.

148. Kiriazis H, Wang K, Xu Q, Gao XM, Ming Z, Su Y, et al. Knockout of $\beta 1$ - and $\beta 2$-adrenoceptors attenuates pressure overloadinduced cardiac hypertrophy and fibrosis. Br J Pharmacol 2008; 153:684-92.

149. Nguyen MN, Su Y, Vizi D, Fang L, Ellims AH, Zhao WB, et al. Mechanisms responsible for increased circulating levels of galectin-3 in heart disease. Sci Rep 2018;8:8213.

150. She G, Hou MC, Zhang Y, Zhang Y, Wang Y, Wang HF, et al. Gal-3 (Galectin-3) and KCa3.1 mediate heterogeneous cell coupling and myocardial fibrogenesis driven by $\beta A R$ ( $\beta$-Adrenoceptor) activation. Hypertension 2020;75:393-404.

151. She G, Ren YJ, Wang Y, Hou MC, Wang HF, Gou W, et al. KCa3.1 channels promote cardiac fibrosis through mediating inflammation and differentiation of monocytes into myofibroblasts in angiotensin II-treated rats. J Am Heart Assoc 2019;8:e010418.

152. Nguyen TP, Xie Y, Garfinkel A, Qu Z, Weiss JN. Arrhythmogenic consequences of myofibroblast-myocyte coupling. Cardiovasc Res 2012;93:242-51.

153. Asazuma-Nakamura Y, Dai P, Harada Y, Jiang Y, Hamaoka K, Takamatsu T. CX43 contributes to TGF- $\beta$ signaling to regulate differentiation of cardiac fibroblasts into myofibroblasts. Exp Cell Res 2009;315:1190-9.

154. Zhang Y, Wang H, Kovacs A, Kanter EM, Yamada KA. Reduced expression of $\mathrm{C} \times 43$ attenuates ventricular remodeling after myocardial infarction via impaired TGF- $\beta$ signaling. Am J Physiol Heart Circ Physiol 2010;298:H477-87.

155. Woodcock EA, Du XJ, Reichelt ME, Graham RM. Cardiac $\alpha 1$-adrenergic drive in pathological remodelling. Cardiovasc Res 2008;77:452-62.

156. Du XJ, Fang L, Gao XM, Kiriazis H, Feng X, Hotchkin E, et al. Genetic enhancement of ventricular contractility protects against pressure-overload-induced cardiac dysfunction. J Mol Cell Cardiol 2004;37:979-87.

157. Jensen BC, O'Connell TD, Simpson PC. $\alpha 1$-Adrenergic receptors in heart failure: the adaptive arm of the cardiac response to chronic catecholamine stimulation. J Cardiovasc Pharmacol 2014;63:291-301.

158. Wang BH, Du XJ, Autelitano DJ, Milano CA, Woodcock EA. Adverse effects of constitutively active $\alpha 1 \mathrm{~B}$-adrenergic receptors after pressure overload in mouse hearts. Am J Physiol Heart Circ Physiol 2000;279:H1079-86.

159. O'Connell TD, Swigart PM, Rodrigo MC, Ishizaka S, Joho S, Turnbull L, et al. $\alpha 1$-adrenergic receptors prevent a maladaptive cardiac response to pressure overload. J Clin Invest 2006;116: 1005-15.

160. Huang Y, Wright CD, Merkwan CL, Baye NL, Liang Q, Simpson PC, et al. An $\alpha 1 \mathrm{~A}$-adrenergic-extracellular signal-regulated kinase survival signaling pathway in cardiac myocytes. Circulation 2007;115:763-72.

161. Myagmar BE, Ismaili T, Swigart PM, Raghunathan A, Baker AJ, Sahdeo $\mathrm{S}$, et al. Coupling to $\mathrm{Gq}$ signaling is required for cardioprotection by an $\alpha 1 \mathrm{~A}$-adrenergic receptor agonist. Circ Res 2019;125:699-706.

162. Shi T, Papay RS, Perez DM. $\alpha 1 A$-Adrenergic receptor prevents cardiac ischemic damage through PKCD/GLUT1/4-mediated glucose uptake. J Recept Signal Transduct Res 2016;36:261-70.

163. Zhao X, Balaji P, Pachon R, Beniamen DM, Vatner DE, Graham RM, et al. Overexpression of cardiomyocyte $\alpha 1 \mathrm{~A}$-adrenergic receptors attenuates postinfarct remodeling by inducing angiogenesis through heterocellular signaling. Arterioscler Thromb Vasc Biol 2015;35:2451-9.

164. Lin F, Owens WA, Chen S, Stevens ME, Kesteven S, Arthur JF, et al. Targeted $\alpha 1 A$-adrenergic receptor overexpression induces enhanced cardiac contractility but not hypertrophy. Circ Res 2001;89:343-50.

165. Du XJ, Gao XM, Kiriazis H, Moore XL, Ming Z, Su Y, et al. Transgenic $\alpha 1 A$-adrenergic activation limits post-infarct ventricular remodeling and dysfunction and improves survival. Cardiovasc Res 2006;71:735-43.

166. Beak J, Huang W, Parker JS, Hicks ST, Patterson C, Simpson PC, et al. An oral selective $\alpha 1 \mathrm{~A}$ adrenergic receptor agonist prevents doxorubicin cardiotoxicity. JACC Basic TransI Sci 2017;2:39-53.

167. Montgomery MD, Chan T, Swigart PM, Myagmar BE, Dash R, Simpson PC. An $\alpha 1 A$ adrenergic receptor agonist prevents acute doxorubicin cardiomyopathy in male mice. PLoS One 2017;12: e0168409.

168. Jensen BC, Swigart PM, De Marco T, Hoopes C, Simpson PC. $\alpha 1$-Adrenergic receptor subtypes in nonfailing and failing human myocardium. Circ Heart Fail 2009;2:654-63.

169. Monto F, Oliver E, Vicente D, Rueda J, Aguero J, Almenar L, et al. Different expression of adrenoceptors and GRKs in the human myocardium depends on heart failure etiology and correlates to clinical variables. Am J Physiol Heart Circ Physiol 2012;303: H368-76. 
170. Janssen PML, Canan BD, Kilic A, Whitson BA, Baker AJ. Human myocardium has a robust $\alpha 1 \mathrm{~A}$-subtype Adrenergic receptor inotropic response. J Cardiovasc Pharmacol 2018;72:136-42.

171. Yu ZY, Tan JC, McMahon AC, lismaa SE, Xiao XH, Kesteven SH, et al. RhoA/ROCK signaling and pleiotropic alpha1A-adrenergic receptor regulation of cardiac contractility. PLoS One 2014;9: e99024.

172. Mohl MC, lismaa SE, Xiao XH, Friedrich O, Wagner S, NikolovaKrstevski V, et al. Regulation of murine cardiac contractility by activation of $\alpha 1 \mathrm{~A}$-adrenergic receptor-operated $\mathrm{Ca}(2+)$ entry. Cardiovasc Res 2011;91:310-9.

173. Du XJ, Dart AM, Riemersma RA, Oliver MF. Sex difference in presynaptic adrenergic inhibition of norepinephrine release during normoxia and ischemia in the rat heart. Circ Res 1991;68: 827-35.

174. Du XJ, Riemersma RA. Effects of presynaptic $\alpha$-adrenoceptors and neuronal reuptake on noradrenaline overflow and cardiac response. Eur J Pharmacol 1992;211:221-6.

175. Altman JD, Trendelenburg AU, MacMillan L, Bernstein D, Limbird $\mathrm{L}$, Starke K, et al. Abnormal regulation of the sympathetic nervous system in $\alpha 2 \mathrm{~A}$-adrenergic receptor knockout mice. Mol Pharmacol 1999;56:154-61.

176. Brede M, Wiesmann F, Jahns R, Hadamek K, Arnolt C, Neubauer S, et al. Feedback inhibition of catecholamine release by two different $\alpha 2$-adrenoreceptor subtypes prevents progression of heart failure. Circulation 2002;106:2491-6.

177. Aggarwal A, Esler MD, Socratous F, Kaye DM. Evidence for functional presynaptic $\alpha 2$ adrenoceptors and their down-regulation in human heart failure. J Am Coll Cardiol 2001;37:1246-51.

178. Kaye DM, Smirk B, Finch S, Williams C, Esler MD. Interaction between cardiac sympathetic drive and heart rate in heart failure: modulation by adrenergic receptor genotype. J Am Coll Cardiol 2004;44:2008-15.

179. Regitz-Zagrosek V, Hocher B, Bettmann M, Brede M, Hadamek K, Gerstner $C$, et al. $\alpha 2 C$-adrenoreceptor polymorphism is associated with improved event-free survival in patients with dilated cardiomyopathy. Eur Heart J 2006;27:454-9.

180. Small KM, Wagoner LE, Levin AM, Kardia SL, Liggett SB. Synergistic polymorphisms of $\beta 1$ - and $\alpha 2 C$-adrenergic receptors and the risk of congestive heart failure. N Engl J Med 2002;347: 1135-42.

181. Rossoni G, Manfredi B, Cavalca V, Razzetti R, Bongrani S, Polvani GL, et al. The aminotetraline derivative (+/-)-(R,S)5,6-dihydroxy-2-methylamino-1,2,3,4-tetrahydro-naphthalene hydrochloride (CHF-1024) displays cardioprotection in postischemic ventricular dysfunction of the rat heart. J Pharmacol Exp Ther 2003;307:633-9.

182. Torp-Pedersen C, Kober L, Carlsen JE, Akkan D, Bruun NE, Dacoronias $\mathrm{D}$, et al. A randomised trial of a pre-synaptic stimulator of DA2-dopaminergic and $\alpha 2$-adrenergic receptors on morbidity and mortality in patients with heart failure. Eur J Heart Fail 2008;10:89-95.

183. Aleong RG, Sauer WH, Robertson AD, Liggett SB, Bristow MR. Adrenergic receptor polymorphisms and prevention of ventricular arrhythmias with bucindolol in patients with chronic heart failure. Circ Arrhythm Electrophysiol 2013;6:137-43.

184. Himura Y, Felten SY, Kashiki M, Lewandowski TJ, Delehanty JM, Liang CS. Cardiac noradrenergic nerve terminal abnormalities in dogs with experimental congestive heart failure. Circulation 1993;88:1299-309.
185. Kimura K, leda M, Fukuda K. Development, maturation, and transdifferentiation of cardiac sympathetic nerves. Circ Res 2012;110:325-36.

186. Backs J, Haunstetter A, Gerber SH, Metz J, Borst MM, Strasser $\mathrm{RH}$, et al. The neuronal norepinephrine transporter in experimental heart failure: evidence for a posttranscriptional downregulation. J Mol Cell Cardiol 2001;33:461-72.

187. Kanazawa H, leda M, Kimura K, Arai T, Kawaguchi-Manabe H, Matsuhashi T, et al. Heart failure causes cholinergic transdifferentiation of cardiac sympathetic nerves via gp130-signaling cytokines in rodents. J Clin Invest 2010;120: 408-21.

188. Du JH, Guan TJ, Zhang H, Xiao H, Han QD, Zhang YY. Phenylarsine oxide inhibited $\beta$-adrenergic receptor-mediated IL- 6 secretion: inhibition of CAMP accumulation and CREB activation in cardiac fibroblasts. Biochem Biophys Res Commun 2007;352:744-9.

189. Eiken HG, Oie E, Damas JK, Yndestad A, Bjerkeli V, Aass H, et al. Myocardial gene expression of leukaemia inhibitory factor, interleukin-6 and glycoprotein 130 in end-stage human heart failure. Eur J Clin Invest 2001;31:389-97.

190. Kreusser MM, Buss SJ, Krebs J, Kinscherf R, Metz J, Katus HA, et al. Differential expression of cardiac neurotrophic factors and sympathetic nerve ending abnormalities within the failing heart. J Mol Cell Cardiol 2008;44:380-7.

191. Jougasaki M, Leskinen H, Larsen AM, Cataliotti A, Chen HH and Burnett JC, Jr. Leukemia inhibitory factor is augmented in the heart in experimental heart failure. Eur J Heart Fail 2003;5: 137-45.

192. Olivas A, Gardner RT, Wang L, Ripplinger CM, Woodward WR, Habecker BA. Myocardial infarction causes transient cholinergic transdifferentiation of cardiac sympathetic nerves via gp130. J Neurosci 2016;36:479-88.

193. Wang L, Olivas A, Francis Stuart SD, Tapa S, Blake MR, Woodward WR, et al. Cardiac sympathetic nerve transdifferentiation reduces action potential heterogeneity after myocardial infarction. Am J Physiol Heart Circ Physiol 2020;318:H558-65.

194. Kiuchi S, Hisatake S, Kabuki T, Oka T, Dobashi S, Fujii T, et al. Effect of switching from cilnidipine to Azelnidipine on cardiac sympathetic nerve function in patients with heart failure preserved ejection fraction. Int Heart I 2018;59:120-5.

195. Kaye DM, Vaddadi G, Gruskin SL, Du XJ, Esler MD. Reduced myocardial nerve growth factor expression in human and experimental heart failure. Circ Res 2000;86:E80-4.

196. Kimura K, Kanazawa H, leda M, Kawaguchi-Manabe H, Miyake Y, Yagi T, et al. Norepinephrine-induced nerve growth factor depletion causes cardiac sympathetic denervation in severe heart failure. Auton Neurosci 2010;156:27-35.

197. Qin F, Vulapalli RS, Stevens SY, Liang CS. Loss of cardiac sympathetic neurotransmitters in heart failure and NE infusion is associated with reduced NGF. Am J Physiol Heart Circ Physiol 2002;282:H363-71.

198. Kreusser MM, Haass M, Buss SJ, Hardt SE, Gerber SH, Kinscherf $\mathrm{R}$, et al. Injection of nerve growth factor into stellate ganglia improves norepinephrine reuptake into failing hearts. Hypertension 2006;47:209-15.

199. Kiriazis H, Du XJ, Feng X, Hotchkin E, Marshall T, Finch S, et al. Preserved left ventricular structure and function in mice with cardiac sympathetic hyperinnervation. Am J Physiol Heart Circ Physiol 2005;289:H1359-65. 
200. Singh S, Sayers S, Walter JS, Thomas D, Dieter RS, Nee LM, et al. Hypertrophy of neurons within cardiac ganglia in human, canine, and rat heart failure: the potential role of nerve growth factor. J Am Heart Assoc 2013;2:e000210.

201. Tan CMJ, Green P, Tapoulal N, Lewandowski AJ, Leeson P, Herring $N$. The role of neuropeptide $Y$ in cardiovascular health and disease. Front Physiol 2018;9:1281.

202. Huang W, Zhang Q, Qi H, Shi P, Song C, Liu Y, et al. Deletion of neuropeptide $Y$ attenuates cardiac dysfunction and apoptosis during acute myocardial infarction. Front Pharmacol 2019;10: 1268.

203. Kalla M, Hao G, Tapoulal N, Tomek J, Liu K, Woodward L, et al. The cardiac sympathetic co-transmitter neuropeptide $Y$ is proarrhythmic following ST-elevation myocardial infarction despite $\beta$-blockade. Eur Heart J 2020;41:2168-79.

204. Ajijola OA, Chatterjee NA, Gonzales MJ, Gornbein J, Liu K, Li D, et al. Coronary sinus neuropeptide $Y$ levels and adverse outcomes in patients with stable chronic heart failure. JAMA Cardiol 2020;5:318-25.

205. Medzikovic L, van Roomen C, Baartscheer A, van Loenen PB, de Vos J, Bakker E, et al. Nur77 protects against adverse cardiac remodelling by limiting neuropeptide $Y$ signalling in the sympathoadrenal-cardiac axis. Cardiovasc Res 2018;114: 1617-28.

206. Aggarwal A, Esler MD, Lambert GW, Hastings J, Johnston L, Kaye DM. Norepinephrine turnover is increased in suprabulbar subcortical brain regions and is related to whole-body sympathetic activity in human heart failure. Circulation 2002; 105:1031-3.

207. Esler MD, Krum H, Schlaich M, Schmieder RE, Bohm M, Sobotka PA, et al. Renal sympathetic denervation for treatment of drug-resistant hypertension: one-year results from the Symplicity HTN-2 randomized, controlled trial. Circulation 2012;126:2976-82.

208. Shen MJ, Zipes DP. Role of the autonomic nervous system in modulating cardiac arrhythmias. Circ Res 2014;114:1004-21.

209. Liao SY, Liu Y, Zuo M, Zhang Y, Yue W, Au KW, et al. Remodelling of cardiac sympathetic re-innervation with thoracic spinal cord stimulation improves left ventricular function in a porcine model of heart failure. Europace 2015;17:1875-83.

210. Issa ZF, Zhou X, Ujhelyi MR, Rosenberger J, Bhakta D, Groh WJ, et al. Thoracic spinal cord stimulation reduces the risk of ischemic ventricular arrhythmias in a postinfarction heart failure canine model. Circulation 2005;111:3217-20.

211. Marcus NJ, Del Rio R, Schultz EP, Xia XH, Schultz HD. Carotid body denervation improves autonomic and cardiac function and attenuates disordered breathing in congestive heart failure. J Physiol 2014;592:391-408.

212. Del Rio R, Marcus NJ, Schultz HD. Carotid chemoreceptor ablation improves survival in heart failure: rescuing autonomic control of cardiorespiratory function. J Am Coll Cardiol 2013;62: 2422-30.

213. Fujii K, Saku K, Kishi T, Oga Y, Tohyama T, Nishikawa T, et al. Carotid body denervation markedly improves survival in rats with hypertensive heart failure. Am J Hypertens 2017;30:791-8.

214. Zhang Y, Popovic ZB, Bibevski S, Fakhry I, Sica DA, Van Wagoner $D R$, et al. Chronic vagus nerve stimulation improves autonomic control and attenuates systemic inflammation and heart failure progression in a canine high-rate pacing model. Circ Heart Fail 2009;2:692-9.

215. Li M, Zheng C, Sato T, Kawada T, Sugimachi M, Sunagawa K. Vagal nerve stimulation markedly improves long-term survival after chronic heart failure in rats. Circulation 2004; 109:120-4.

216. Machhada A, Hosford PS, Dyson A, Ackland GL, Mastitskaya S, Gourine AV. Optogenetic stimulation of vagal efferent activity preserves left ventricular function in experimental heart failure. JACC Basic Transl Sci 2020;5:799-810.

217. Liao SY, Zhen Z, Liu Y, Au KW, Lai WH, Tsang A, et al. Improvement of myocardial function following catheter-based renal denervation in heart failure. JACC Basic Transl Sci 2017;2:270-81.

218. Sharp TE, 3rd, Polhemus DJ, Li Z, Spaletra P, Jenkins JS, Reilly JP, et al. Renal denervation prevents heart failure progression via inhibition of the renin-angiotensin system. J Am Coll Cardiol 2018;72:2609-21.

219. Li C, Xia W, Wang L, Zhang J, He Q, Liu Y, et al. Effect of renal denervation on cardiac function and inflammatory factors in heart failure after myocardial infarction. J Cardiovasc Pharmacol 2020;76:602-9.

220. Chen WJ, Liu H, Wang ZH, Liu C, Fan JQ, Wang ZL, et al. The impact of renal denervation on the progression of heart failure in a canine model induced by right ventricular rapid pacing. Front Physiol 2020;10:1625.

221. Zhang WH, Zhou QN, Lu YM, Li YD, Zhang L, Zhang JH, et al. Renal denervation reduced ventricular arrhythmia after myocardial infarction by inhibiting sympathetic activity and remodeling. J Am Heart Assoc 2018;7:e009938.

222. Zhang B, Li X, Chen C, Jiang W, Lu D, Liu Q, et al. Renal denervation effects on myocardial fibrosis and ventricular arrhythmias in rats with ischemic cardiomyopathy. Cell Physiol Biochem 2018;46:2471-9.

223. Polhemus DJ, Trivedi RK, Sharp TE, Li Z, Goodchild TT, Scarborough A, et al. Repeated cell transplantation and adjunct renal denervation in ischemic heart failure: exploring modalities for improving cell therapy efficacy. Basic Res Cardiol 2019;114:9.

224. Gold MR, Van Veldhuisen DJ, Hauptman PJ, Borggrefe M, Kubo $\mathrm{SH}$, Lieberman RA, et al. Vagus nerve stimulation for the treatment of heart failure: the INOVATE-HF trial. J Am Coll Cardiol 2016;68:149-58.

225. Zipes DP, Neuzil P, Theres H, Caraway D, Mann DL, Mannheimer C, et al. Determining the feasibility of spinal cord neuromodulation for the treatment of chronic systolic heart failure: the DEFEAT-HF study. JACC Heart Fail 2016;4:129-36.

226. Hopper I, Gronda E, Hoppe UC, Rundqvist B, Marwick TH, Shetty S, et al. Sympathetic response and outcomes following renal denervation in patients with chronic heart failure: 12-month outcomes from the Symplicity HF feasibility study. J Card Fail 2017;23:702-7.

227. Bendary A, Bendary M, Salem M. Autonomic regulation device therapy in heart failure with reduced ejection fraction: a systematic review and meta-analysis of randomized controlled trials. Heart Fail Rev 2019;24:245-54.

228. Jiang Z, Zhou X, Chen C, Wang Y, Fang P, Geng J, et al. Renal denervation for ventricular arrhythmia in patients with implantable cardioverter defibrillators. Int Heart J 2018;59:328-32. 
229. Mangmool S, Denkaew T, Parichatikanond W, Kurose H. $\beta$-Adrenergic receptor and insulin resistance in the heart. Biomol Ther (Seoul) 2017;25:44-56.

230. Cole SW, Sood AK. Molecular pathways: $\beta$-adrenergic signaling in cancer. Clin Cancer Res 2012;18:1201-6.

231. Xu Q, Jennings NL, Sim K, Chang L, Gao XM, Kiriazis H, et al. Pathological hypertrophy reverses $\beta 2$-adrenergic receptorinduced angiogenesis in mouse heart. Physiol Rep 2015;3. https://doi.org/10.14814/phy2.12340.

232. Kotecha D, Holmes J, Krum H, Altman DG, Manzano L, Cleland JG, et al. Efficacy of $\beta$ blockers in patients with heart failure plus atrial fibrillation: an individual-patient data meta-analysis. Lancet 2014;384:2235-43.

233. Nagatomo Y, Yoshikawa T, Okamoto H, Kitabatake A, Hori M, Investigators JC. Anemia is associated with blunted response to beta-blocker therapy using carvedilol- insights from Japanese chronic heart failure (J-CHF) study. Circ J 2018;82:691-8.

234. Wisler JW, DeWire SM, Whalen EJ, Violin JD, Drake MT, Ahn S, et al. $A$ unique mechanism of $\beta$-blocker action: carvedilol stimulates beta-arrestin signaling. Proc Natl Acad Sci U S A 2007;104:16657-62.

235. Kim J, Grotegut CA, Wisler JW, Mao L, Rosenberg PB, Rockman $H A$, et al. The $\beta$-arrestin-biased $\beta$-adrenergic receptor blocker carvedilol enhances skeletal muscle contractility. Proc Natl Acad Sci U S A 2020;117:12435-43.

236. Carr R, 3rd, Schilling J, Song J, Carter RL, Du Y, Yoo SM, et al. $\beta$-arrestin-biased signaling through the beta2-adrenergic receptor promotes cardiomyocyte contraction. Proc Natl Acad Sci U S A 2016;113:E4107-16.

237. Jimenez-Marrero S, Moliner P, Rodriguez-Costoya I, Enjuanes C, Alcoberro L, Yun S, et al. Sympathetic activation and outcomes in chronic heart failure: does the neurohormonal hypothesis apply to mid-range and preserved ejection fraction patients? Eur J Intern Med 2020;81:60-6.

238. Vergaro G, Aimo A, Prontera C, Ghionzoli N, Arzilli C, Zyw L, et al. Sympathetic and renin-angiotensin-aldosterone system activation in heart failure with preserved, mid-range and reduced ejection fraction. Int J Cardiol 2019;296:91-7. 